\title{
ENTRAMADO PRODUCTIVO DEL PARTIDO DE GENERAL SAN MARTÍN. ANÁLISIS DE CASO
}

\author{
ENRIQUE DÉNTICE \\ CLARA LÓPEZ \\ LETICIA BUSELLINI \\ UNIVERSIDAD NACIONAL DE SAN MARTÍN (UNSAM) \\ ESCUELA DE ECONOMÍA Y NEGOCIOS (EEYN) \\ CENTRO DE INVESTIGACIÓN Y MEDICIÓN ECONÓMICA (CIME)
}

ARGENTINA

"Nuestra recompensa se encuentra en el esfuerzo y no en el resultado. Un esfuerzo total es una victoria completa". Mahatma Gandhi. 


\section{RESUMEN}

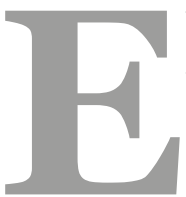

l presente estudio tiene por objeto determinar si la composición industrial del partido de San Martín ha mutado o no en relación a la estructura productiva que presentaba en el Censo Industrial realizado una década atrás para dicho Municipio.

La información recabada a través de la actualización de la base de datos, con que contaba la Municipalidad, fue analizada comparativamente con datos del EMI (Estimador Mensual Industrial). Con esto se verificó la continuidad de la composición industrial del Partido y realizar una comparación de la conformación manufacturera a nivel país. La clasificación sectorial obtenida le brinda claros datos a los representantes políticos del Partido de cuál es la especialización de las empresas asentadas en el territorio.

De la cantidad de industrias que se encuentran activas actualmente dentro del partido se desprende que Villa Lynch concentra el 28\% de las industrias (348 establecimientos), le sigue Villa Ballester con el 16\% (202 establecimientos) y en tercer lugar, Villa Maipú con el 15\% (191 establecimientos). Esta información tiene gran utilidad para el Municipio ya que deberían enfocar las políticas públicas según zonas en función a las necesidades de cada localidad.

El trabajo clasifica a las industrias por tamaño, cantidad de personal ocupado, rubro, origen de insumos y destino de sus ventas.

En pocas palabras es una visión del mapa productivo del partido de Gral. San Martín.

Palabras clave: actividad industrial, desarrollo productivo, sectores económicos, desarrollo local, estructura productiva.

\section{ABSTRACT}

This study aims to determine whether the industrial composition of the San Martin municipality has mutated or not in relation to the production structure that it had in the Industrial Census, conducted a decade ago for that municipality. The information, gathered through the updating of the Municipality's database, was analyzed comparatively to data from EMI (Monthy Industrial Estimator). With this the continuity of the industrial composition of the Municipality was verified and a comparison of manufacturing conformation at country level was carried. Sectoral classification gives the Minicipality's political representatives clear data of companies' specialization within the territory. Out from the number of industries currently active within the municipality, it can be highlighted that Villa Lynch concentrates $28 \%$ of all industries (348 establishments), followed by Villa Ballester with $16 \%$ (202 establishments) and thirdly, Villa Maipú with 15\% (191 establishments). This information is of great use to the municipality for their public policies should be area-focused, according to the needs of each locality. The work 
classifies industries by size, number of employed persons, category, input source and destination of their sales.In short it is a vision of the production map of Gral. San Martin.

Keywords: industrial, productive development, economic sectors, local development, production structure.

Los párrafos que anteceden responden las preguntas que aquí se enumeran:

1. ¿Por qué se lleva a cabo el estudio?

2. ¿Cuál es la utilidad de los nuevos conocimientos con los datos locales?

3. ¿Que permite su transferencia al medio?

\section{ESTRUCTURA DE LA INDUSTRIA}

La primera comparación resulta del análisis de la composición productiva nacional con la de la industria local.

Los ponderadores de los distintos sectores que componen el Estimador Mensual Industrial (EMI) se calculan en función del valor agregado industrial en el año base. Los ponderadores expresados en porcentaje indican la participación de cada uno de los bloques sectoriales en el nivel general.

Respecto de la industria nacional, tres rubros explican el 50\% de la estructura: 19,3\% alimentos y bebidas; $15,5 \%$ sustancias y productos químicos y 15,1\% metalmecánica excluida la industria automotriz.

Respecto del partido de General San Martín, los tres rubros que explican más del 50\% de la estructura productiva son: metalmecánica excluida la industria automotriz con $28,8 \%$; productos de caucho y plástico con 14,1\% y productos textiles con 10,7\%. 
Cuadro 1. Estructura de la Industria Nacional y del

Partido de General San Martín - en porcentaje del total

\begin{tabular}{|c|c|c|c|}
\hline & \multirow{2}{*}{$\begin{array}{c}\text { EMI Nacional Base } 2006 \\
\%\end{array}$} & \multicolumn{2}{|c|}{ San Martín Dic-13 } \\
\hline & & $\%$ & empresas \\
\hline Rubros & 100,0 & 100,0 & 1.244 \\
\hline 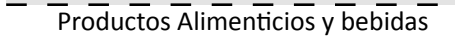 & $19 \overline{13}$ & $\overline{8}, 4$ & $\overline{105}$ \\
\hline Productos del Tabaco & 0,7 & 0,0 & 0 \\
\hline Productos Textiles & 2,0 & 10,7 & 133 \\
\hline Papel y Cartón & 3,0 & 2,9 & 36 \\
\hline Edición e Impresión & 5,7 & 3,9 & 48 \\
\hline Refinación del Petróleo & 8,4 & 0,0 & 0 \\
\hline Sustancias y Productos Químicos & 15,5 & 7,9 & 98 \\
\hline Productos de Caucho y Plástico & 4,2 & 14,1 & 176 \\
\hline Productos Minerales no Metálicos & 4,2 & 1,5 & 19 \\
\hline Industrias Metálicas Básicas & 10,8 & 1,0 & 13 \\
\hline Vehículos Automotores & 11,1 & 2,9 & 36 \\
\hline Metalmecánica exc. Ind. Automotriz & 15,1 & 28,8 & 358 \\
\hline Cuero & & 2,7 & 34 \\
\hline Madera y Muebles & & 7,5 & 93 \\
\hline Electrónica & & 7,6 & 95 \\
\hline
\end{tabular}

Fuente: Elaboración propia en base a INDEC - EMI y Relevamiento Industrias del Partido de Gral. San Martín (Diciembre 2013).

Cuadro 2. Primeros tres rubros de la Industria Nacional y del Partido de General San Martín - en porcentaje del total

\begin{tabular}{|c|c|c|c|}
\hline EMI & \multicolumn{3}{|c|}{ San Martín } \\
\hline Rubros & $\%$ & - _ _ Rubros & - $\%$ \\
\hline Productos Alimenticios y bebidas & 19,3 & Metalmecánica exc. Ind. Automotriz & 28,8 \\
\hline Sustancias y Productos Químicos & 15,5 & Caucho y plástico & 14,1 \\
\hline Metalmecánica exc. Ind. Automotriz & 15,1 & Textil & 10,7 \\
\hline Resto & 50,1 & Resto & 46,4 \\
\hline
\end{tabular}

Fuente: Elaboración propia en base a INDEC - EMI y Relevamiento Industrias del Partido de Gral. San Martín (Diciembre 2013)

Gráfico 1. Primeros tres rubros de la Industria Nacional y del

Partido de General San Martín - en porcentaje del total

Primeros tres rubros a nivel nacional y en el Partido de Gral. San Martín en \% del total, según rubros del EMI

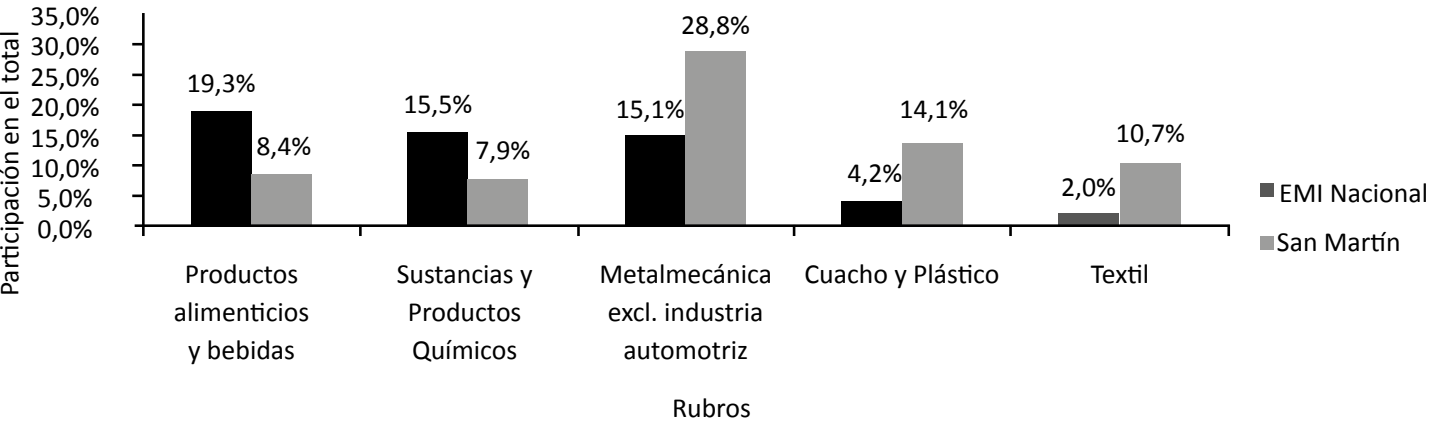

Fuente: Elaboración propia en base a INDEC - EMI y Relevamiento Industrias del Partido de Gral. San Martín (Diciembre 2013) 
Si se agrupa a las industrias en grandes rubros se puede observar, en esa misma línea, que la participación de la industria metalmecánica en el Partido de General San Martín sigue superando su participación a nivel nacional. Lo mismo ocurre con los rubros: plástico y caucho y textil, confecciones y cuero, donde la diferencia porcentual se hace más amplia respecto de la estructura productiva del país.

Cuadro 3. Grandes rubros de la Industria Nacional y del Partido de San Martín en porcentaje del total.

\begin{tabular}{|c|c|c|}
\hline \multicolumn{2}{|l|}{ EMI } & San Martín \\
\hline - _ - _ nubros _ & \% & - $\%$ \\
\hline Metalmecánica & 37,0 & 40,4 \\
\hline Refinación de petróleo y químicos & 23,9 & 7,9 \\
\hline Alimentos, bebidas y tabaco & 20,0 & 8,4 \\
\hline Plástico y Caucho & 4,2 & 14,1 \\
\hline Textil, confecciones y cuero & 2,0 & 13,4 \\
\hline Resto & 12,9 & 15,8 \\
\hline Total & 100,0 & 100,0 \\
\hline
\end{tabular}

Fuente: Elaboración propia en base a INDEC - EMI y Relevamiento Industrias del Partido de Gral. San Martín (Diciembre 2013).

Gráfico 2. Grandes rubros de la Industria Nacional y del Partido de San Martín en porcentaje del total.

Grandes rubos a nivel nacional y en el Partido de General San Martin en \% del total, según los primeros 5 rubros agrupados.

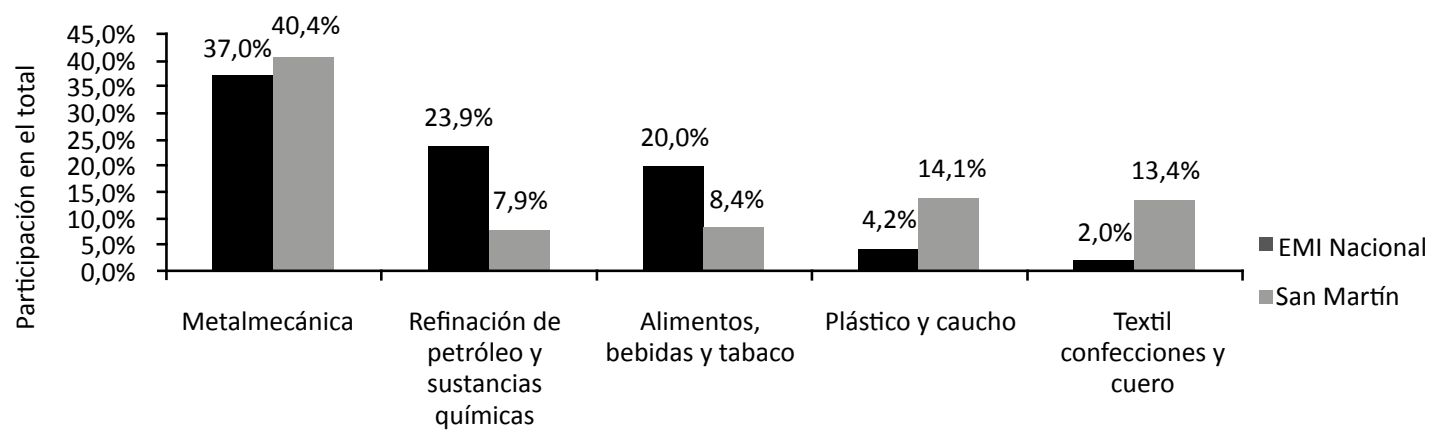

Rubros

Fuente: Elaboración propia en base a INDEC - EMI y Relevamiento Industrias del Partido de Gral. San Martín (Diciembre 2013).

\section{LOCALIZACIÓN DE LA INDUSTRIA}

Del presente relevamiento se desprende que Villa Lynch concentra el 28\% de las industrias (348 establecimientos), le sigue Villa Ballester con el 16\% (202 establecimientos) y en tercer lugar, Villa Maipú con el 15\% (191 establecimientos). 
Respecto de la localización de los tres primeros rubros en estas zonas de mayor concentración industrial, la distribución se presenta de la siguiente manera:

Cuadro 4. Localización de los primeros tres rubros del Partido de General San Martín en porcentaje del total.

\begin{tabular}{ccccc|c}
\hline & Villa Lynch & Villa Ballester & Villa Maipú & Resto & Total \\
\hline Metalmecánica exc. Ind. Automotriz & $30 \%$ & $23 \%$ & $16 \%$ & $30 \%$ & $\mathbf{1 0 0 \%}$ \\
Caucho y plástico & $28 \%$ & $9 \%$ & $18 \%$ & $45 \%$ & $\mathbf{1 0 0 \%}$ \\
Textil & $52 \%$ & $12 \%$ & $5 \%$ & $\mathbf{3 2 \%}$ & $\mathbf{1 0 0 \%}$ \\
Resto & $21 \%$ & $15 \%$ & $16 \%$ & $47 \%$ & $\mathbf{1 0 0 \%}$ \\
\hline Total & $\mathbf{2 8 \%}$ & $\mathbf{1 6 \%}$ & $\mathbf{1 5 \%}$ & $\mathbf{4 0 \%}$ & $\mathbf{1 0 0 \%}$
\end{tabular}

Fuente: Relevamiento Industrias del Partido de Gral. San Martín (Diciembre 2013)

Del cuadro anterior se desprende que la zona ciertamente más industrial es Villa Lynch, concentrando más del 50\% de la industria textil, el 30\% de la metalmecánica excluida la automotriz y el $28 \%$ de la industria del plástico y caucho.

Gráfico 3. Localización de los primeros tres rubros del Partido de General San Martín en porcentaje del total.

\section{Localización de los tres primeros rubros en \% del total, según rubros del EMI}

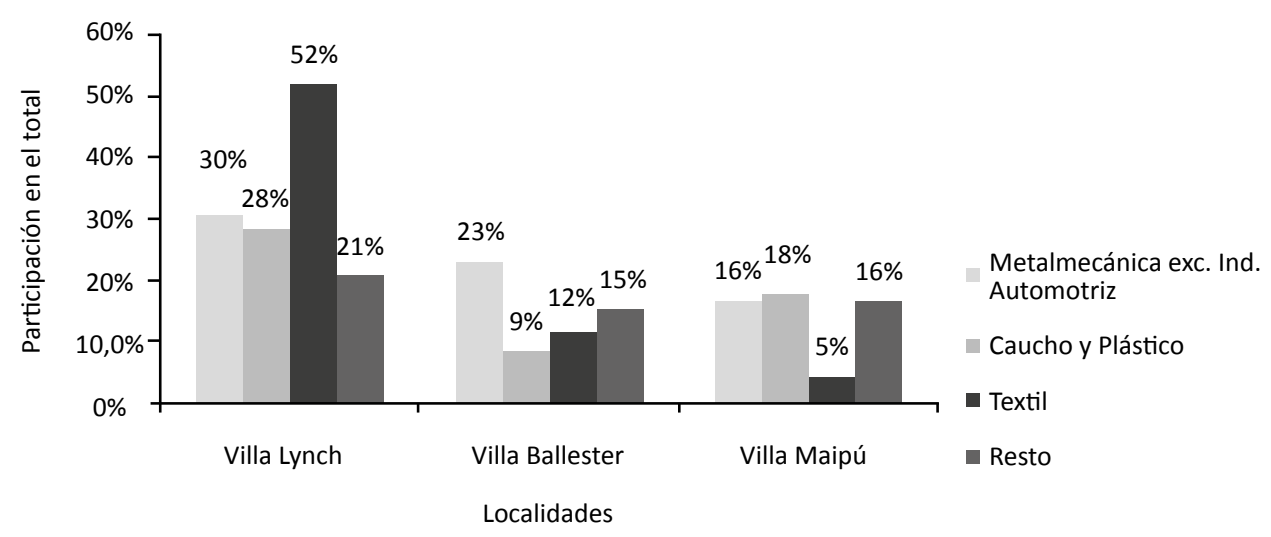

Fuente: Relevamiento Industrias del Partido de Gral. San Martín (Diciembre 2013).

$\mathrm{Al}$ agrupar las industrias en 8 grandes rubros, la localidad de Villa Lynch sigue concentrando la mayor participación en establecimientos industriales de metalmecánica, plástico y caucho y textil. Le sigue Villa Maipú en metalmecánica y plástico y caucho y Villa Ballester con textil.

Sin embargo, cabe aclarar que para el rubro plástico y caucho se detectan 16 y 17 establecimientos en las localidades de San Andrés y José León Suárez respectivamente, superando a los 15 establecimientos de ese rubro presentes en la localidad de Villa Ballester. 
Cuadro 5. Localización de las empresas según 8 grandes rubros - en porcentaje del total.

\begin{tabular}{|c|c|c|c|c|c|}
\hline & Villa Lynch & Villa Ballester & Villa Maipú & Resto & Total \\
\hline Metalmecánica & $25,4 \%$ & $18,7 \%$ & $15,1 \%$ & $40,8 \%$ & $100,0 \%$ \\
\hline Plástico y caucho & $28,4 \%$ & $8,5 \%$ & $17,6 \%$ & $45,5 \%$ & $100,0 \%$ \\
\hline Textil, confecciones y cuero & $49,4 \%$ & $11,4 \%$ & $8,4 \%$ & $30,7 \%$ & $100,0 \%$ \\
\hline Alimentos, bebidas y tabaco & $17,1 \%$ & $21,9 \%$ & $18,1 \%$ & $42,9 \%$ & $100,0 \%$ \\
\hline $\begin{array}{l}\text { Refinación de petróleo y } \\
\text { sustancias químicas }\end{array}$ & $32,7 \%$ & $17,3 \%$ & $18,4 \%$ & $31,6 \%$ & $100,0 \%$ \\
\hline Madera y muebles & $16,1 \%$ & $18,3 \%$ & $20,4 \%$ & $45,2 \%$ & $100,0 \%$ \\
\hline Pasta celulósica, papel e impresiones & $23,8 \%$ & $13,1 \%$ & $13,1 \%$ & $50,0 \%$ & $100,0 \%$ \\
\hline Otras manufacturas & $15,8 \%$ & $31,6 \%$ & $15,8 \%$ & $36,8 \%$ & $100,0 \%$ \\
\hline Total & $28,0 \%$ & $16,2 \%$ & $15,4 \%$ & $40,4 \%$ & $100,0 \%$ \\
\hline
\end{tabular}

Fuente: Relevamiento Industrias del Partido de Gral. San Martín (Diciembre 2013).

Gráfico 4. Localización de las empresas según 8 grandes rubros - en porcentaje del total.

\section{Localización de las empresas} en \% del total, según 8 rubros agrupados

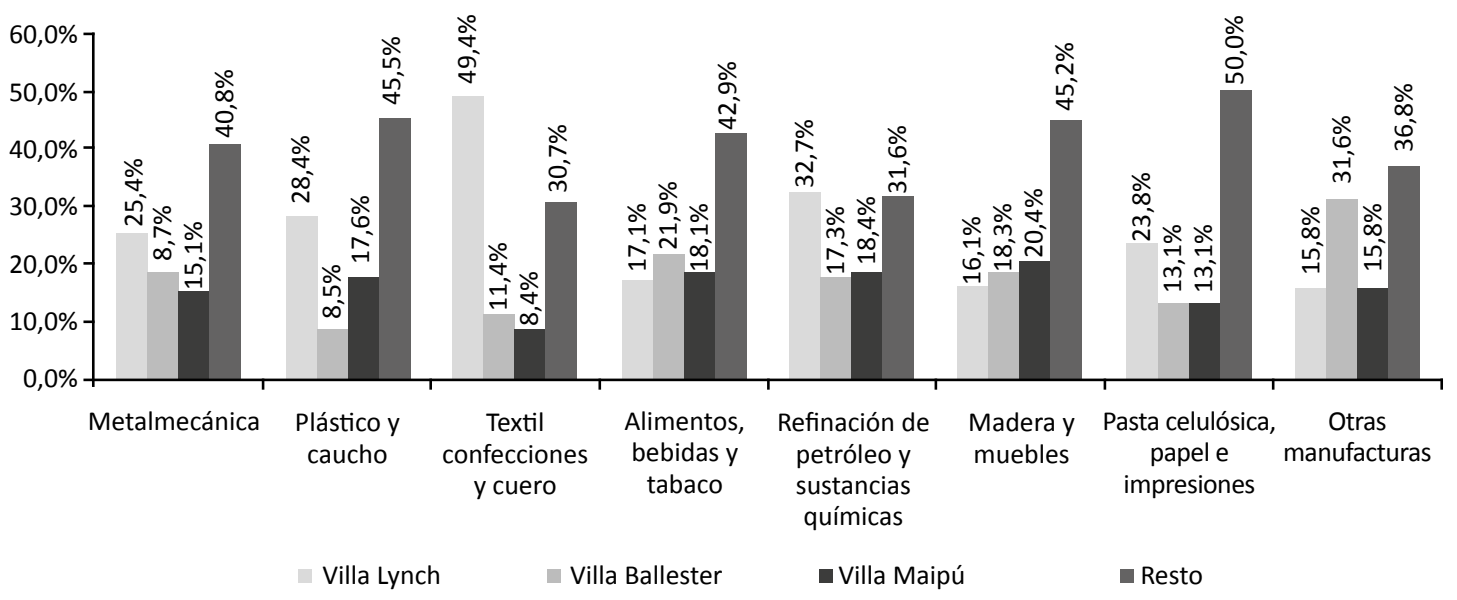

Fuente: Relevamiento Industrias del Partido de Gral. San Martín (Diciembre 2013).

En cuanto a la composición industrial de cada localidad analizada, Villa Lynch presenta, de 348 empresas relevadas, 128 pertenecientes al rubro metalmecánico, 82 al textil y 50 al plástico y caucho, conformando entre los tres el $75 \%$ de la estructura productiva de la localidad. Asimismo, en Villa Ballester se relevaron 202 empresas, de las cuales 94 corresponden al rubro metalmecánico, 19 al textil y 15 al plástico y caucho y suman el 63\% de la composición industrial. Respecto de Villa Maipú, la misma presenta 191 empresas relevadas, de las cuales 76 son del rubro metalmecánico, 31 de plástico y caucho y 14 textiles, lo cual también representa el 63\% de la estructura productiva de la localidad. 
Cuadro 6. Composición industrial por localidad, según 8 grandes rubros en porcentaje del total

\begin{tabular}{|c|c|c|c|c|}
\hline----------- & Villa Lynch & Villa Ballester & Villa Maipú & Resto $-\ldots-$ \\
\hline Metalmecánica & $36,8 \%$ & $46,5 \%$ & $39,8 \%$ & $40,8 \%$ \\
\hline Plástico y caucho & $14,4 \%$ & $7,4 \%$ & $16,2 \%$ & $15,9 \%$ \\
\hline Textil, confecciones y cuero & $23,6 \%$ & $9,4 \%$ & $7,3 \%$ & $10,1 \%$ \\
\hline Alimentos, bebidas y tabaco & $5,2 \%$ & $11,4 \%$ & $9,9 \%$ & $8,9 \%$ \\
\hline $\begin{array}{l}\text { Refinación de petróleo y } \\
\text { sustancias químicas }\end{array}$ & $9,2 \%$ & $8,4 \%$ & $9,4 \%$ & $6,2 \%$ \\
\hline Madera y muebles & $4,3 \%$ & $8,4 \%$ & $9,9 \%$ & $8,3 \%$ \\
\hline Pasta celulósica, papel e impresiones & $5,7 \%$ & $5,4 \%$ & $5,8 \%$ & $8,3 \%$ \\
\hline Otras manufacturas & $0,9 \%$ & $3,0 \%$ & $1,6 \%$ & $1,4 \%$ \\
\hline Total & $100,0 \%$ & $100,0 \%$ & $100,0 \%$ & $100,0 \%$ \\
\hline
\end{tabular}

Fuente: Relevamiento Industrias del Partido de Gral. San Martín (Diciembre 2013).

Gráfico 5. Composición industrial por localidad, según 8 grandes rubros en porcentaje del total.

\section{Composición industrial por localidad} en \% del total, según 8 rubros agrupados.

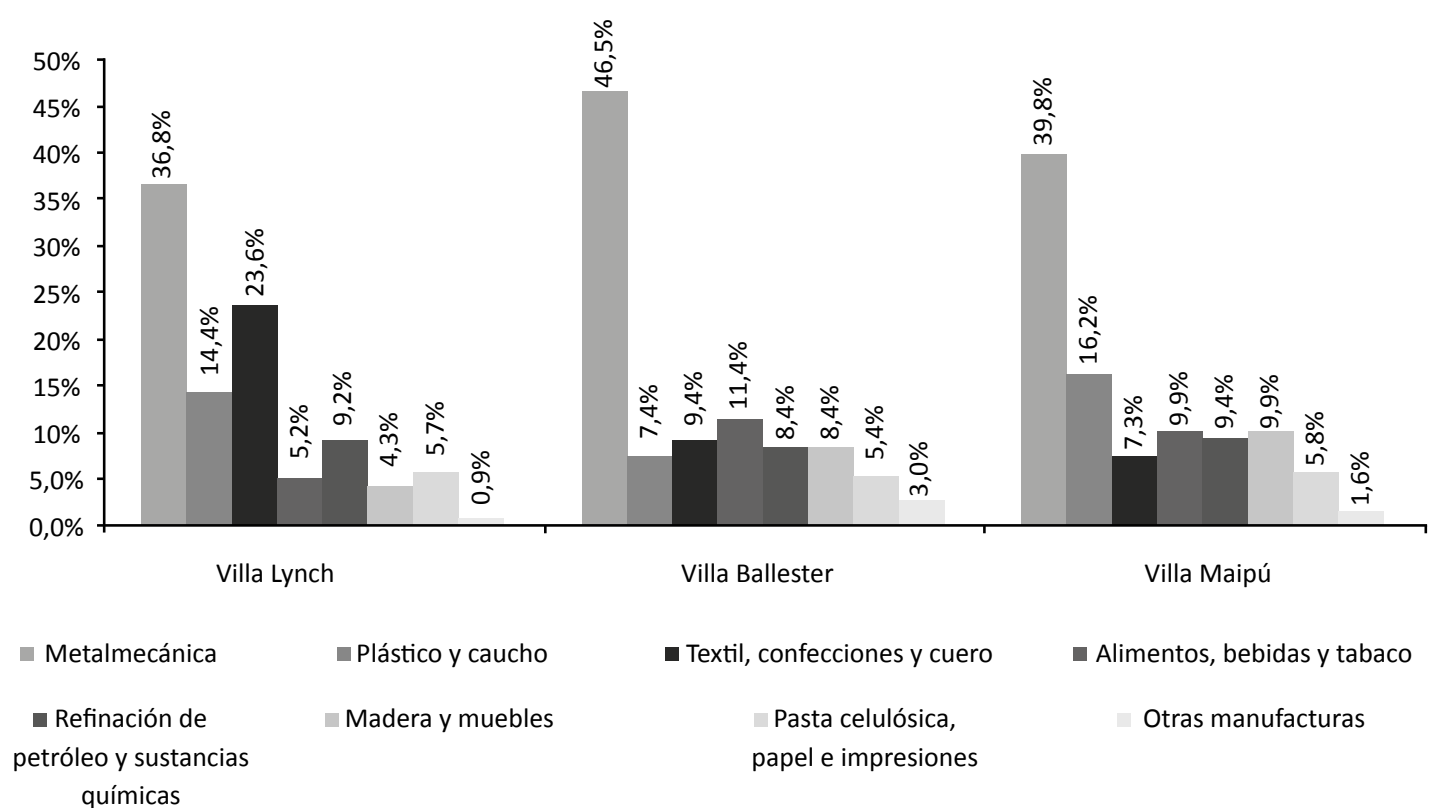

Fuente: Relevamiento Industrias del Partido de Gral. San Martín (Diciembre 2013). 


\section{TAMAÑO DE LA INDUSTRIA SEGÚN CANTIDAD DE EMPLEADOS}

Para realizar esta comparación con el tamaño de las empresas a nivel nacional, se consideraron los 19 rubros del CLANAE, presentes en la estructura productiva del partido de General San Martín, tomando la misma base a nivel nacional para 2012, último dato anual disponible en el Observatorio de Empleo y Dinámica Empresarial del Ministerio de Trabajo, Empleo y Seguridad Social de la Nación.

El tamaño de las empresas fue definido en base al siguiente criterio:

- De 1 a 50 empleados: pequeña

- De 51 a 200 empleados: mediana

- Más de 200 empleados: grande

Del análisis se desprende una composición similar en cuanto al tamaño de las empresas, tanto a nivel nacional como local. Puede verse que respecto de las pequeñas, a nivel nacional el porcentaje es levemente superior, con 93,3\% contra 91,2\% a nivel local. Contrariamente, el partido de General San Martín presenta una mayor participación de empresas tanto medianas como grandes, con un $6,3 \%$ y $2,5 \%$ respectivamente, contra $5,2 \%$ y $1,4 \%$ a nivel nacional.

De acuerdo al tamaño según rubros, se presentan algunas diferencias en aquellos relacionados a la industria metalmecánica.

Respecto de los rubros: fabricación de maquinaria y aparatos eléctricos; fabricación de maquinaria y equipos; fabricación de vehículos automotores, remolques y semirremolques y fabricación de equipos de transporte se muestra una menor participación de empresas de tamaño pequeño respecto del nivel nacional, con un 72\%, 67\%, 74\% y 80\% respectivamente, contra $92,5 \%, 85 \%, 92 \%$, y $91,5 \%$ a nivel país. Esta diferencia se presenta por la existencia de un mayor porcentaje de empresas medianas en los rubros de fabricación de maquinaria y equipos eléctricos (28\%) y fabricación de vehículos automotores (16\%). Asimismo, en el rubro fabricación de maquinaria y equipo se manifiesta un muy alto porcentaje de grandes empresas en relación al nivel nacional, sin embargo se debe a que está directamente relacionado con el tamaño de la muestra en ese rubro (3 empresas relevadas).

Otros rubros a destacar son sustancias y productos químicos y fabricación de productos de caucho y plástico, donde se presenta un mayor porcentaje de empresas grandes respecto del total nacional $8 \%$ vs $5 \%$ y $4 \%$ vs $1 \%$ respectivamente.

Sin embargo, si el análisis se realiza agrupando a las industrias en los 8 grandes rubros se reducen las diferencias porcentuales, pero del mismo modo surge una mayor presencia de empresas medianas respecto de la composición de la industria nacional. 
Cuadro 7. Tamaño de las empresas del Partido de General San Martín, según 8 grandes rubros - en valores absolutos y porcentaje del total.

\begin{tabular}{|c|c|c|c|c|c|c|c|c|}
\hline \multirow{2}{*}{$\begin{array}{c}\text { San Martín } \\
\text { Rubros }\end{array}$} & \multicolumn{4}{|c|}{ En valores absolutos } & \multicolumn{4}{|c|}{ En porcentaje } \\
\hline & Pequeña & Mediana & Grande & Total & Pequeña & Mediana & Grande & Total \\
\hline Metalmecánica & 330 & 22 & 6 & 358 & $92,2 \%$ & $6,1 \%$ & $1,7 \%$ & $100,0 \%$ \\
\hline Plástico y caucho & 97 & 10 & 4 & 111 & $87,4 \%$ & $9,0 \%$ & $3,6 \%$ & $100,0 \%$ \\
\hline Textil, confecciones y cuero & 118 & 8 & 3 & 129 & $91,5 \%$ & $6,2 \%$ & $2,3 \%$ & $100,0 \%$ \\
\hline Alimentos, bebidas y tabaco & 68 & 4 & 2 & 74 & $91,9 \%$ & $5,4 \%$ & $2,7 \%$ & $100,0 \%$ \\
\hline $\begin{array}{l}\text { Refinación de petróleo y } \\
\text { sustancias químicas }\end{array}$ & 56 & 3 & 5 & 64 & $87,5 \%$ & $4,7 \%$ & $7,8 \%$ & $100,0 \%$ \\
\hline Madera y muebles & 74 & 4 & 1 & 79 & $93,7 \%$ & $5,1 \%$ & $1,3 \%$ & $100,0 \%$ \\
\hline Pasta celulósica, papel e impresiones & 50 & 3 & 1 & 54 & $92,6 \%$ & $5,6 \%$ & $1,9 \%$ & $100,0 \%$ \\
\hline Otras manufacturas & 8 & 1 & 0 & 9 & $88,9 \%$ & $11,1 \%$ & $0,0 \%$ & $100,0 \%$ \\
\hline Total & 801 & 55 & 22 & 878 & $91,2 \%$ & $6,3 \%$ & $2,5 \%$ & $100,0 \%$ \\
\hline
\end{tabular}

Fuente: Relevamiento Industrias del Partido de Gral. San Martín (Diciembre 2013).

Cuadro 8. Tamaño de las empresas a nivel nacional, según 8 grandes rubros en valores absolutos y porcentaje del total.

\begin{tabular}{|c|c|c|c|c|c|c|c|c|}
\hline \multirow{2}{*}{$\begin{array}{l}\text { Nacional } \\
\text { Rubros }\end{array}$} & \multicolumn{4}{|c|}{ En valores absolutos } & \multicolumn{4}{|c|}{ En porcentaje } \\
\hline & Pequeña & Mediana & Grande & Total & Pequeña & Mediana & Grande & Total \\
\hline Metalmecánica & 16.799 & 925 & 229 & 17.953 & $93,6 \%$ & $5,2 \%$ & $1,3 \%$ & $100,0 \%$ \\
\hline Plástico y caucho & 2.859 & 258 & 34 & 3.151 & $90,7 \%$ & $8,2 \%$ & $1,1 \%$ & $100,0 \%$ \\
\hline Textil, confecciones y cuero & 8.165 & 427 & 101 & 8.693 & $93,9 \%$ & $4,9 \%$ & $1,2 \%$ & $100,0 \%$ \\
\hline Alimentos, bebidas y tabaco & 13.523 & 751 & 254 & 14.528 & $93,1 \%$ & $5,2 \%$ & $1,7 \%$ & $100,0 \%$ \\
\hline $\begin{array}{l}\text { Refinación de petróleo y } \\
\text { sustancias químicas }\end{array}$ & 2.133 & 249 & 115 & 2.497 & $85,4 \%$ & $10,0 \%$ & $4,6 \%$ & $100,0 \%$ \\
\hline Madera y muebles & 3.637 & 116 & 20 & 3.773 & $96,4 \%$ & $3,1 \%$ & $0,5 \%$ & $100,0 \%$ \\
\hline Pasta celulósica, papel e impresiones & 4.512 & 239 & 62 & 4.813 & $93,7 \%$ & $5,0 \%$ & $1,3 \%$ & $100,0 \%$ \\
\hline Otras manufacturas & 3.250 & 113 & 19 & 3.382 & $96,1 \%$ & $3,3 \%$ & $0,6 \%$ & $100,0 \%$ \\
\hline Total & 54.878 & 3.078 & 834 & 58.790 & $93,3 \%$ & $5,2 \%$ & $1,4 \%$ & $100,0 \%$ \\
\hline
\end{tabular}


Gráfico 6. Tamaño de las empresas del Partido de General San Martín, según 8 grandes rubros - en porcentaje del total.

Tamaño de las empresas del Partido de Gral. San Martin en \% del total, según 8 rubros agrupados

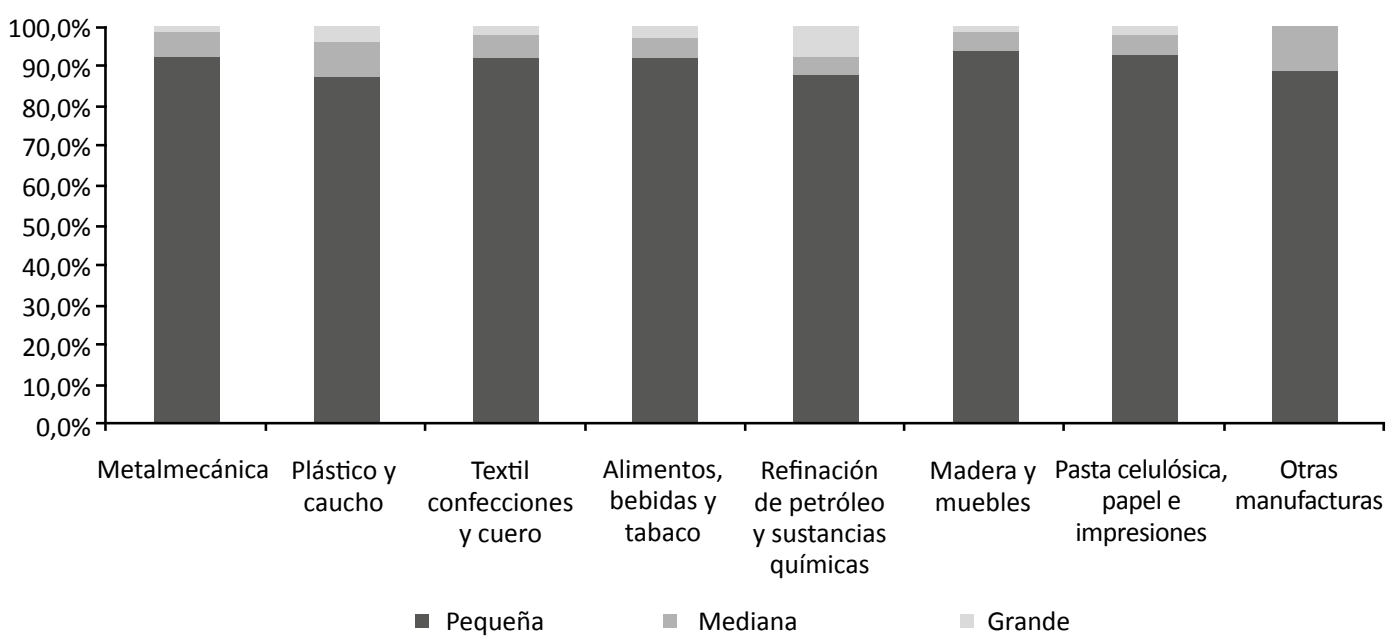

Fuente: Relevamiento Industrias del Partido de Gral. San Martín (Diciembre 2013).

Gráfico 7. Tamaño de las empresas del Partido de General San Martín, según 8 grandes rubros - en porcentaje del total.

Tamaño de las empresas a nivel nacional en \% del total, según 8 rubros agrupados

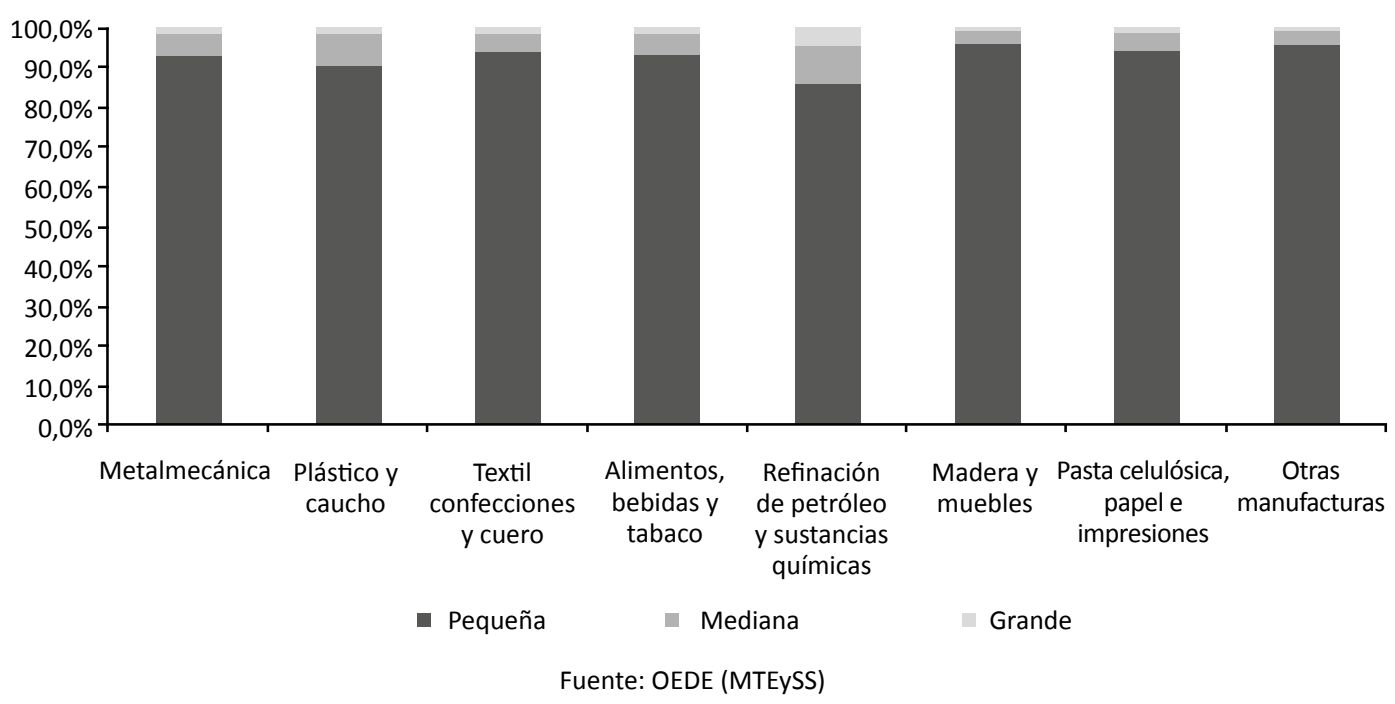


En cuanto al total de las industrias de tamaño pequeño, los rubros de mayor preponderancia en el partido representan el $41 \%$, el $12 \%$ y el $15 \%$ de esta composición. Bajo el mismo criterio de alta participación de estos rubros en las industrias de tamaño mediano, se detecta una presencia del 40\%, 18\% y 14,5\% para la metalmecánica, plástico y caucho y textil, confecciones y cuero.

Considerando la composición de las industrias de tamaño pequeño y mediano, se percibe una mayor participación de los dos primeros grandes rubros (metalmecánico y plásticos) respecto de la participación de estos rubros a nivel nacional. De manera inversa, la participación de la industria alimenticia en los diversos tamaños de la industria es altamente superior a nivel nacional que en el Partido de General San Martín.

La participación de los rubros metalmecánico y refinación de petróleo y sustancias químicas en las industrias de mayor tamaño alcanza el 50\% de la composición de las grandes empresas del partido.

Cuadro 9. Composición de las empresas por tamaño del Partido de General San Martín, según 8 grandes rubros - en valores absolutos y porcentaje del total.

\begin{tabular}{|c|c|c|c|c|c|c|c|}
\hline \multirow{2}{*}{$\begin{array}{c}\text { San Martín } \\
\text { Rubros }\end{array}$} & \multicolumn{4}{|c|}{ En valores absolutos } & \multicolumn{3}{|c|}{ En porcentaje } \\
\hline & Pequeña & Mediana & Grande & Total & Pequeña & Mediana & Grande \\
\hline Metalmecánica & 330 & 22 & 6 & 358 & $41,2 \%$ & $40,0 \%$ & $27,3 \%$ \\
\hline Plástico y caucho & 97 & 10 & 4 & 111 & $12,1 \%$ & $18,2 \%$ & $18,2 \%$ \\
\hline Textil, confecciones y cuero & 118 & 8 & 3 & 129 & $14,7 \%$ & $14,5 \%$ & $13,6 \%$ \\
\hline Alimentos, bebidas y tabaco & 68 & 4 & 2 & 74 & $8,5 \%$ & $7,3 \%$ & $9,1 \%$ \\
\hline $\begin{array}{l}\text { Refinación de petróleo y } \\
\text { sustancias químicas }\end{array}$ & 56 & 3 & 5 & 64 & $7,0 \%$ & $5,5 \%$ & $22,7 \%$ \\
\hline Madera y muebles & 74 & 4 & 1 & 79 & $9,2 \%$ & $7,3 \%$ & $4,5 \%$ \\
\hline Pasta celulósica, papel e impresiones & 50 & 3 & 1 & 54 & $6,2 \%$ & $5,5 \%$ & $4,5 \%$ \\
\hline Otras manufacturas & 8 & 1 & 0 & 9 & $1,0 \%$ & $1,8 \%$ & $0,0 \%$ \\
\hline Total & 801 & 55 & 22 & 878 & $100,0 \%$ & $100,0 \%$ & $100,0 \%$ \\
\hline
\end{tabular}

Fuente: Relevamiento Industrias del Partido de Gral. San Martín (Diciembre 2013).

Cuadro 10. Composición de las empresas por tamaño a nivel nacional, según 8 grandes rubros - en valores absolutos y porcentaje del total.

\begin{tabular}{|c|c|c|c|c|c|c|c|}
\hline \multirow{2}{*}{$\begin{array}{l}\text { Nacional } \\
\text { Rubros }\end{array}$} & \multicolumn{4}{|c|}{ En valores absolutos } & \multicolumn{3}{|c|}{ En porcentaje } \\
\hline & Pequeña & Mediana & Grande & Total & Pequeña & Mediana & Grande \\
\hline Metalmecánica & 16.799 & 925 & 229 & 17.953 & $30,6 \%$ & $30,1 \%$ & $27,5 \%$ \\
\hline Plástico y caucho & 2.859 & 258 & 34 & 3.151 & $5,2 \%$ & $8,4 \%$ & $4,1 \%$ \\
\hline Textil, confecciones y cuero & 8.165 & 427 & 101 & 8.693 & $14,9 \%$ & $13,9 \%$ & $12,1 \%$ \\
\hline Alimentos, bebidas y tabaco & 13.523 & 751 & 254 & 14.528 & $24,6 \%$ & $24,4 \%$ & $30,5 \%$ \\
\hline $\begin{array}{l}\text { Refinación de petróleo y } \\
\text { sustancias químicas }\end{array}$ & 2.133 & 249 & 115 & 2.497 & $3,9 \%$ & $8,1 \%$ & $13,8 \%$ \\
\hline Madera y muebles & 3.637 & 116 & 20 & 3.773 & $6,6 \%$ & $3,8 \%$ & $2,4 \%$ \\
\hline Pasta celulósica, papel e impresiones & 4.512 & 239 & 62 & 4.813 & $8,2 \%$ & $7,8 \%$ & $7,4 \%$ \\
\hline Otras manufacturas & 3.250 & 113 & 19 & 3.382 & $5,9 \%$ & $3,7 \%$ & $2,3 \%$ \\
\hline Total & 54.878 & 3.078 & 834 & 58.790 & $100,0 \%$ & $100,0 \%$ & $100,0 \%$ \\
\hline
\end{tabular}




\section{EMPLEO}

Para el presente análisis se consideró la caracterización y evolución del empleo registrado para el tercer trimestre de 2013, último dato disponible en el Observatorio de Empleo y Dinámica Empresarial del Ministerio de Trabajo, Empleo y Seguridad Social, comparándola con el total de personal ocupado en las industrias del Partido de General San Martín, a Diciembre de 2013.

En cuanto a la composición del empleo a nivel local se encuentra en línea con la composición de la estructura productiva. Se presenta un mayor porcentaje que a nivel nacional en la fabricación de plástico y caucho, con un $17,5 \%$ contra un $5,2 \%$, seguidamente de un $14,2 \%$ para la fabricación de productos elaborados de metal contra un 7,6\% y un 12,7\% para la producción textil contra un 5,4\%. Asimismo, en los demás rubros vinculados a la industria metalmecánica también presentan un leve porcentaje superior en cuanto a participación de empleo respecto del nivel nacional.

Si consideramos la agrupación en los 8 grandes rubros, puede observarse una marcada participación del empleo industrial en los tres rubros destacados en el partido de General San Martín respecto de la participación del empleo industrial a nivel nacional. De manera inversa, se presenta una muy alta participación del rubro alimentos en el empleo industrial a nivel nacional, no así en el partido.

Gráfico 8. Personal ocupado en la industria en el Partido de General San Martín y a nivel nacional - en porcentajes del total.

\section{Participación en el empleo industrial 2013 en \% del total, según 8 rubros agrupados}

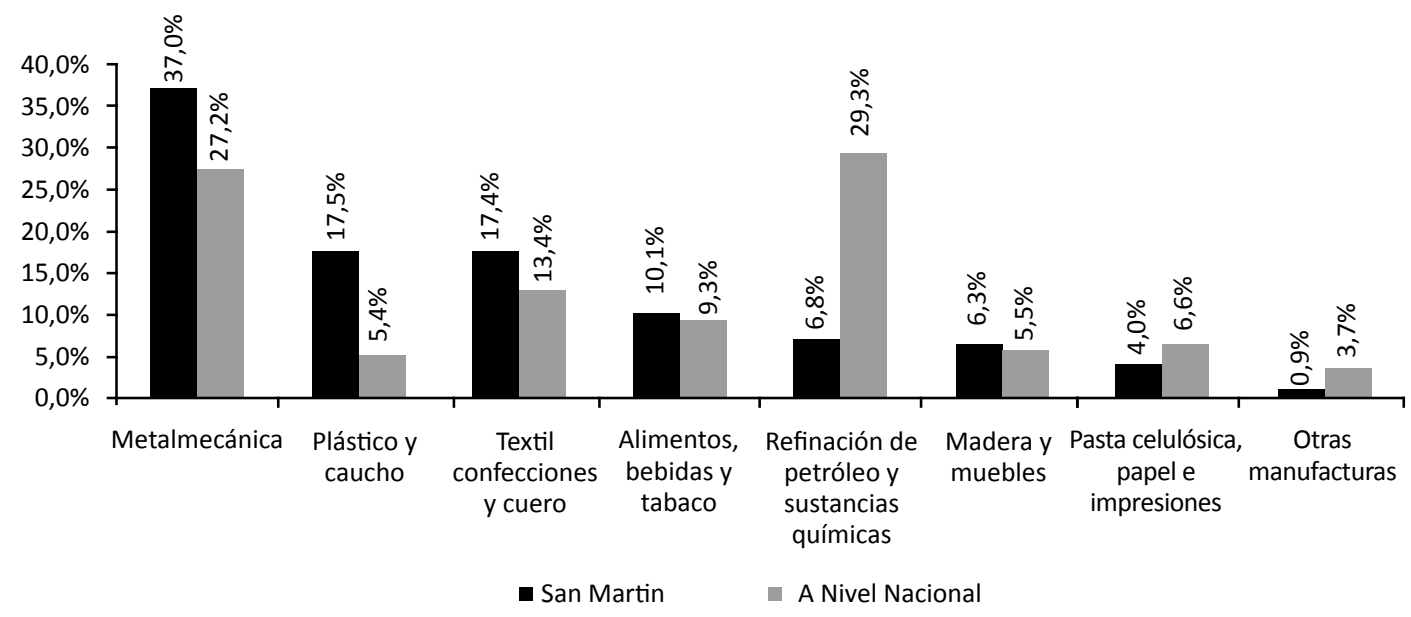

Fuente: Relevamiento Industrias del Partido de Gral. San Martín (Diciembre 2013) y OEDE (MTEySS). 


\section{COMERCIO EXTERIOR}

Respecto las exportaciones de las empresas del partido, dicho análisis de basó en las respuestas del relevamiento de empresas sobre expectativas, el cual fue respondido por 692 de las empresas relevadas. Esta cuestión aplicó al 19,5\% de empresas (135).

Considerando los 19 rubros del CLANAE, pudo observarse que el 51\% de las empresas del rubro fabricación de maquinaria y equipo exporta, le sigue el rubro fabricación de vehículos automotores con un 48\%, luego el rubro de fabricación de maquinaria y aparatos eléctricos con un $31 \%$. A estos rubros similares, continúan fabricación de papel y sustancias y productos químicos, ambos con un $26 \%$.

$\mathrm{Al}$ agrupar los rubros en los 8 grandes grupos, se puede advertir que más del 20\% de las empresas de los rubros metalmecánico, plástico y caucho y refinación de petróleo y sustancias químicas exportan, siendo muy baja la presencia de exportaciones en la industria alimenticia.

Gráfico 9. Empresas exportadoras del Partido de General San Martín

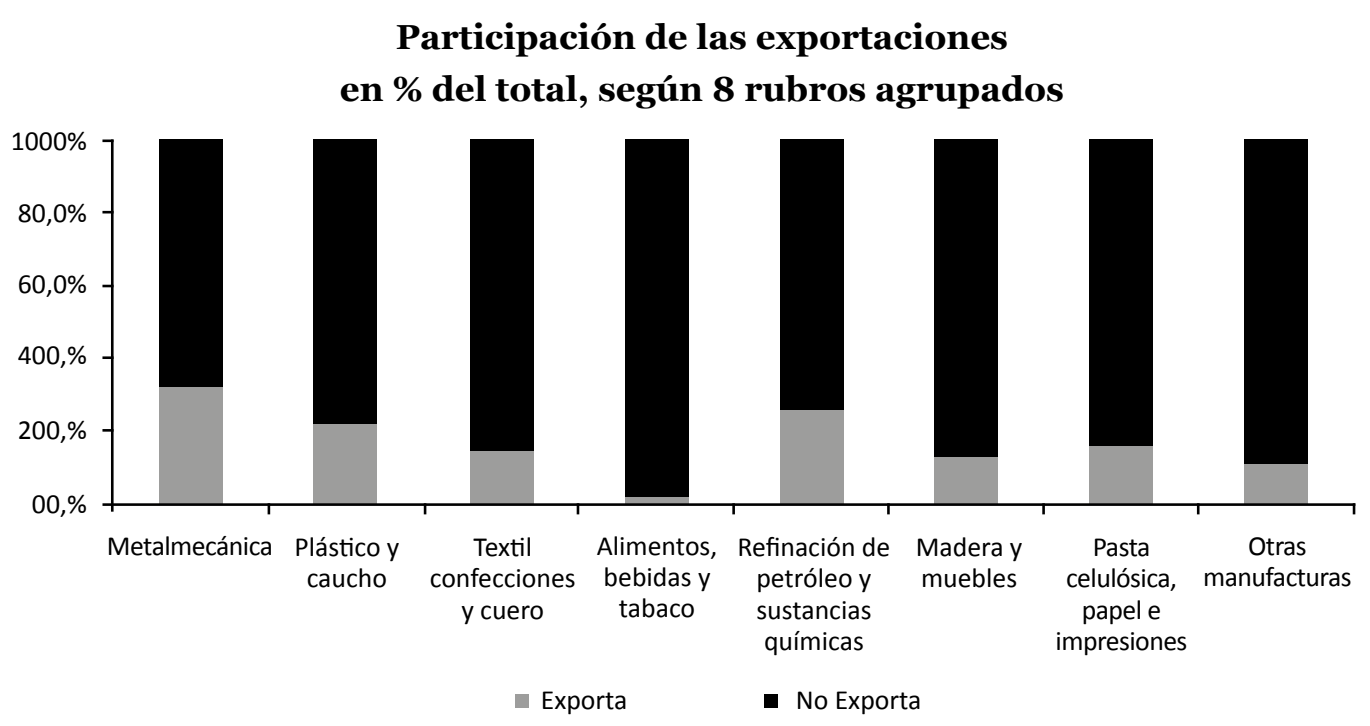

Fuente: Relevamiento Industrias del Partido de Gral. San Martín (Diciembre 2013) y OEDE (MTEySS).

Comparando con la composición de las MOI a nivel nacional, se puede observar una alta presencia de exportaciones de la industria metalmecánica y de productos químicos y conexos al igual que en el partido de General San Martín, en el cual también se destaca la participación de las exportaciones para el rubro de la industria del papel. 
Cuadro 11. Participación de los diversos rubros en las exportaciones MOI a nivel nacional.

\begin{tabular}{cc} 
Rubros & En porcentaje \\
Productos químicos y conexos & $21,0 \%$ \\
Materias plásticas artificiales & $5,1 \%$ \\
Caucho y sus manufacturas & $1,5 \%$ \\
Manufacturas de cuero, marroquinería & $0,2 \%$ \\
Papel, cartón, impresos y publicaciones & $1,9 \%$ \\
Textiles y confecciones & $1,2 \%$ \\
Calzado y sus partes componentes & $0,1 \%$ \\
Manufacturas de piedra, yeso, etc & $0,7 \%$ \\
Piedras y metales preciosos & $9,5 \%$ \\
Metales comunes y sus manufacturas & $10,4 \%$ \\
Máquinas, aparatos y materiales eléctricos & $8,8 \%$ \\
Material de transporte terrestre & $35,5 \%$ \\
Vehículos de navegación aérea, marítima y fluvial & $1,7 \%$ \\
Resto de Mol & $2,4 \%$ \\
\hline Total & $100,0 \%$
\end{tabular}

Fuente: Información Económica al día - Ministerio de Economía y Finanzas Públicas.

Respecto las importaciones de las empresas del partido, dicho análisis también se basó en las respuestas del relevamiento de empresas sobre expectativas, el cual fue respondido por el 691 de las empresas relevadas. Esta cuestión aplicó al 34\% de empresas (234).

Del gráfico se desprende una relación directa entre las empresas exportadoras y su necesidad de importar, ya sea bienes de capital o intermedios para poder realizar su producción.

Gráfico 10. Empresas que importan del Partido de General San Martín

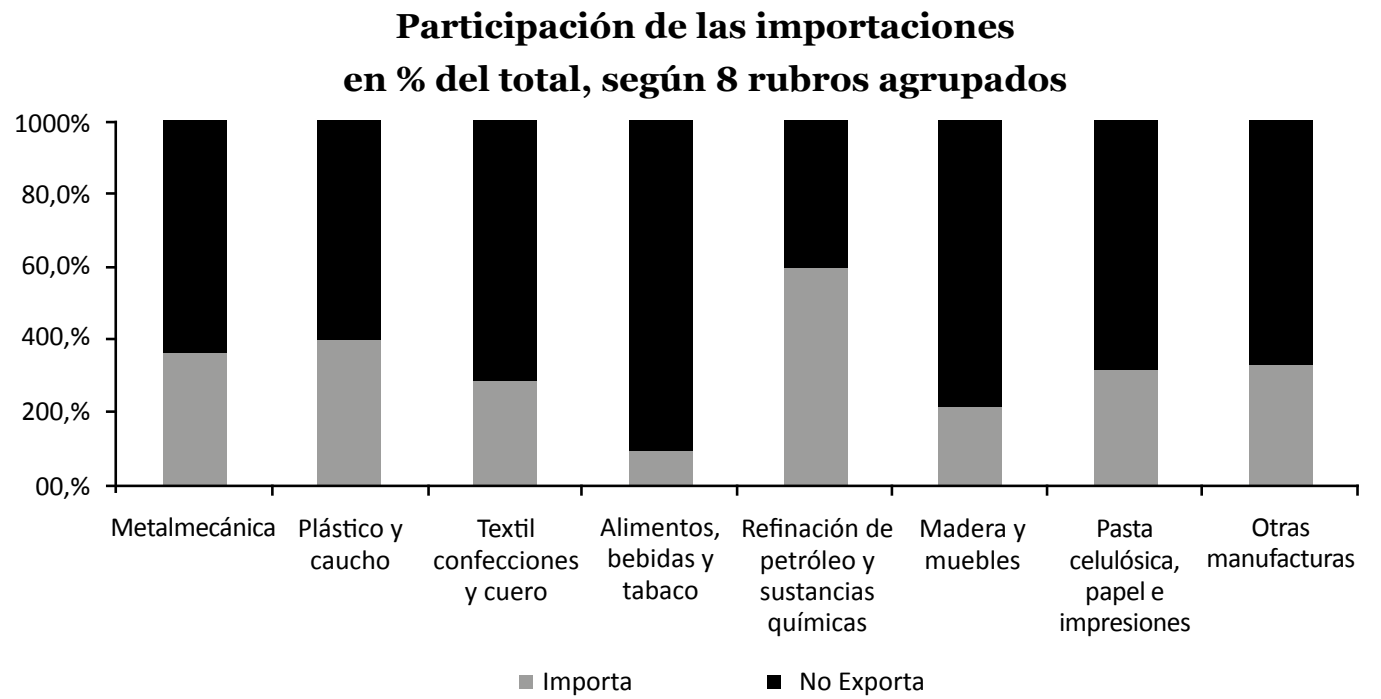

Fuente: Relevamiento Industrias del Partido de Gral. San Martín (Diciembre 2013). 


\section{CAPACIDAD INSTALADA}

En cuanto a la capacidad instalada de las empresas del partido, a través de las respuestas del relevamiento se pudo obtener que el 34\% de las empresas utilizó el 100\% de su capacidad instalada durante el último trimestre de 2013. Si se consideran los 19 rubros del CLANAE, puede detectarse una subutilización de la capacidad en rubros como fabricación de vehículos; muebles; metales comunes y maquinaria y equipo.

En esa misma línea, al agrupar en los 8 grandes rubros, se percibe que la industria metalmecánica y muebles y madera son quienes presentan una menor utilización de su capacidad instalada.

En cuanto a las expectativas de utilización de capacidad instalada, el $44 \%$ de las empresas del partido manifestó que las mismas no han variado. Si lo comparamos con el resultado del EMI sobre las Perspectivas para el primer trimestre de 2014 respecto del primer trimestre de 2013, el 83\% de las empresas no advirtió cambios en la utilización de la capacidad instalada; el 9,2\% preveía una suba, en tanto el 7,8\% anticipó una disminución.

Con relación a la utilización de la capacidad instalada para el primer trimestre de 2014 respecto del trimestre anterior, el 87,9\% de las firmas la consideró adecuada, el 8,1\% opinó que era excesiva y para el $4 \%$ insuficiente.

Respecto del nivel de utilización de la capacidad instalada para el primer trimestre de 2014, el 35,4\% de las firmas opinó que utilizaría entre un 80\% al 100\% de su capacidad; otro $43,4 \%$ anticipó que utilizaría entre un $60 \%$ al $80 \%$ de su capacidad, en tanto el $21,2 \%$ de las empresas ubicó al nivel de por debajo del $60 \%$.

Gráfico 11. Utilización de la capacidad instalada de las empresas del Partido de General San Martín.

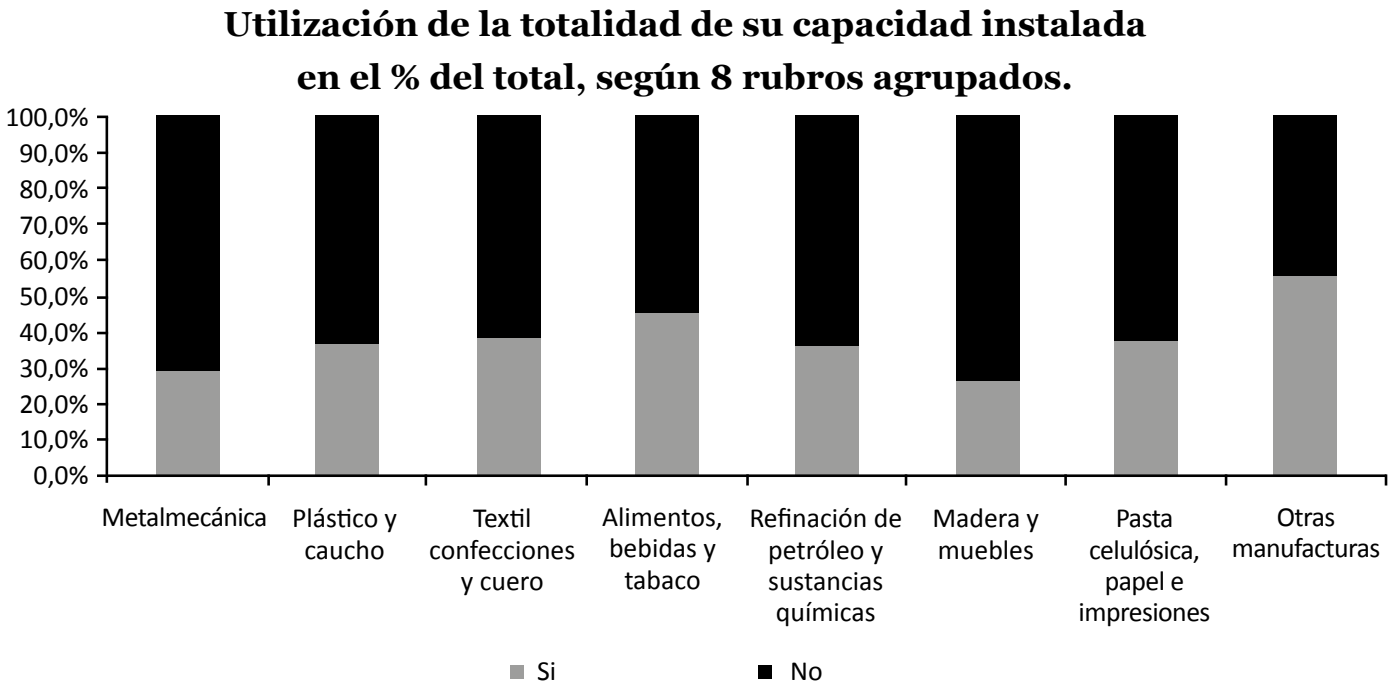

Fuente: Relevamiento Industrias del Partido de Gral. San Martín (Diciembre 2013). 


\section{VENTAS AL MERCADO INTERNO}

Respecto de las expectativas sobre las ventas al mercado interno, se muestra una tendencia a la baja para el $47 \%$ del total de empresas relevadas, acentuándose en los rubros muebles y madera y alimentos, pero también en los rubros metalmecánicos y de sustancias químicas.

En comparación con la información presentada en el EMI de Diciembre de 2013, el 81,8\% de las empresas preveía un ritmo estable en la demanda interna para el primer trimestre de 2014, el 10,1\% anticipaba una suba y el 8,1\% una disminución.

Gráfico 12. Expectativas sobre las ventas al mercado interno de las empresas del Partido de General San Martín.

\section{Expectativas sobre las ventas al mercado interno respecto del} año anterior en \% del total, según 8 rubros agrupados.

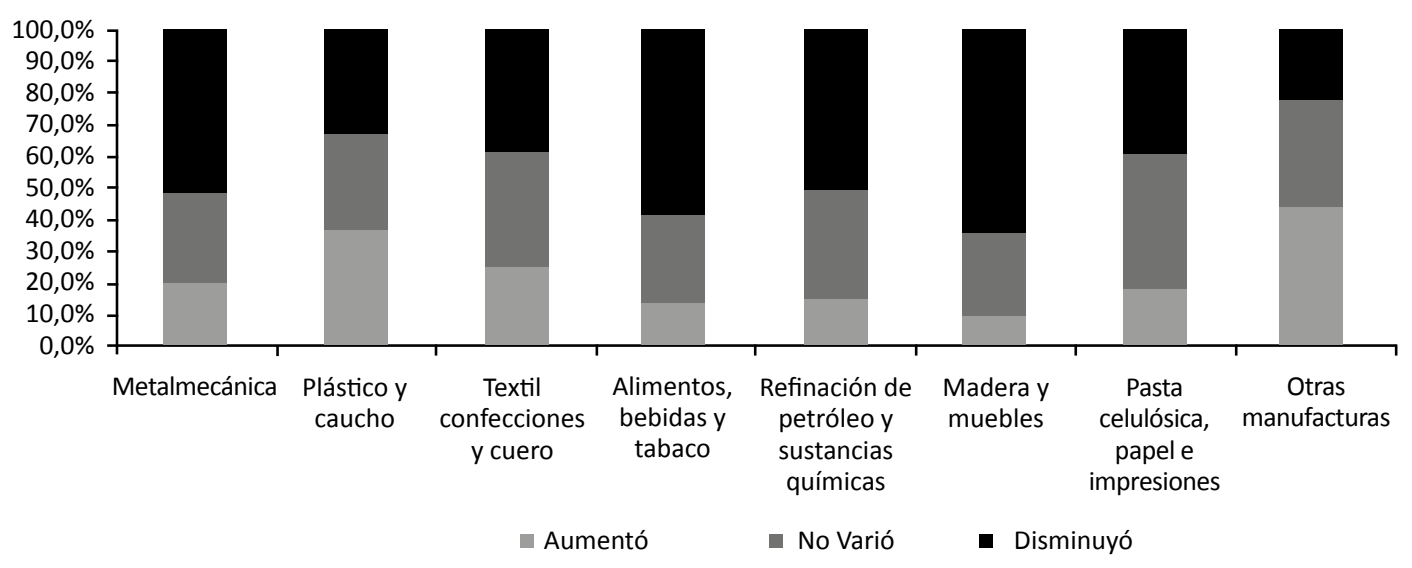

Fuente: Relevamiento Industrias del Partido de Gral. San Martín (Diciembre 2013).

\section{EXPECTATIVAS SOBRE EL TRATAMIENTO DEL STOCK DE PRODUCTOS TERMINADOS}

A nivel local, considerando sólo a las empresas que aplican en este punto, el $49 \%$ de las mismas no esperaba cambios en su stock de productores terminados respecto del año anterior. 
Respecto de las expectativas sobre el stock de productos terminados no se verifica variación para la fabricación metales comunes; equipos y aparatos de comunicación y equipos de transporte. Sí, se manifiesta una disminución de stock de productos terminados para los rubros vinculados a muebles y madera y también para la fabricación de maquinaria y equipo, considerando los 19 rubros del CLANAE.

$\mathrm{Al}$ agrupar en los 8 grandes rubros, se detecta una mayor disminución de stock de productos terminados para muebles y madera.

A nivel nacional, según el EMI a Diciembre de 2013, el 87,7\% de las empresas no esperaba cambios en los stocks de productos terminados con relación al primer trimestre del año anterior; el $8,2 \%$ anticipaba una baja y el 4,1\% esperaba un aumento.

Gráfico 13. Expectativas sobre el stock de productos terminados de las empresas del Partido de General San Martín que aplican en el análisis.

\section{Stock de productos terminados respecto del año anterior en base a las empresas que aplicanen \% del total, según 8 rubros agrupados.}

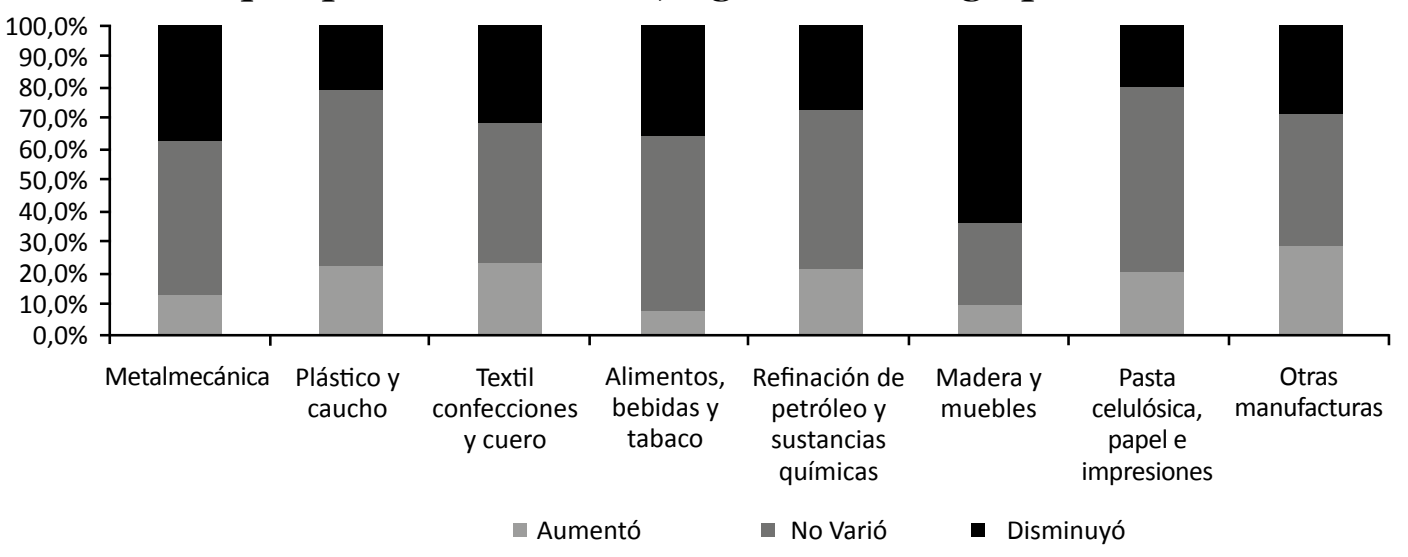

Fuente: Relevamiento Industrias del Partido de Gral. San Martín (Diciembre 2013). 
Gráfico 14. Stock de productos terminados de las empresas del Partido de General San Martín en base a la totalidad de empresas relevadas.

\section{Stock de productos terminados respecto del año anterior en base a la totalidad de empresas relevadas en \% del total, según 8 rubros agrupados.}

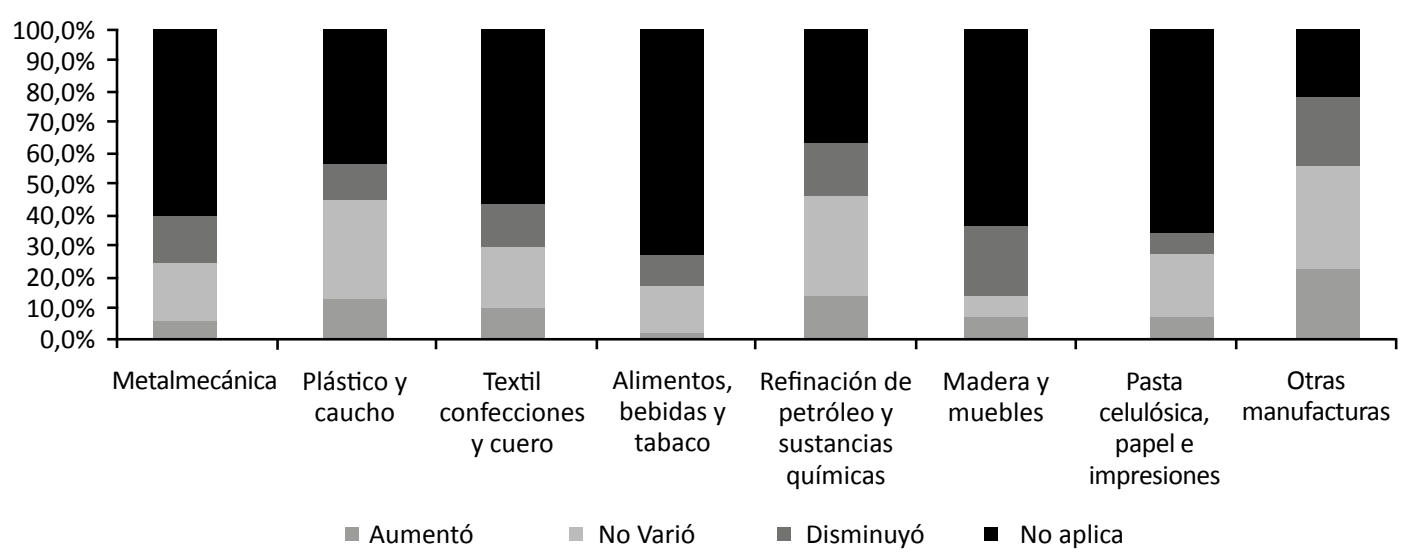

Fuente: Relevamiento Industrias del Partido de Gral. San Martín (Diciembre 2013).

\section{PERSPECTIVAS}

\section{NECESIDAD DE CRÉDITO}

Respecto de la necesidad de crédito, un 67\% de empresas informó que cree que no variará, sin embargo para los rubros fabricación de equipos y aparatos para comunicaciones, bebidas y plástico y caucho, un alto porcentaje afirma que se incrementará su necesidad al mismo, si se consideran los 19 rubros del CLANAE.

$\mathrm{Al}$ agrupar en 8 grandes rubros, se detecta que el 44\% de las industrias del plástico y caucho manifiesta que la necesidad de acceso al crédito aumentará, seguido por la industria textil con un 33\% y refinación de productos de petróleo y sustancias químicas con un 30\%. 
Gráfico 15. Perspectivas sobre la necesidad de crédito de las empresas del Partido de General San Martín.

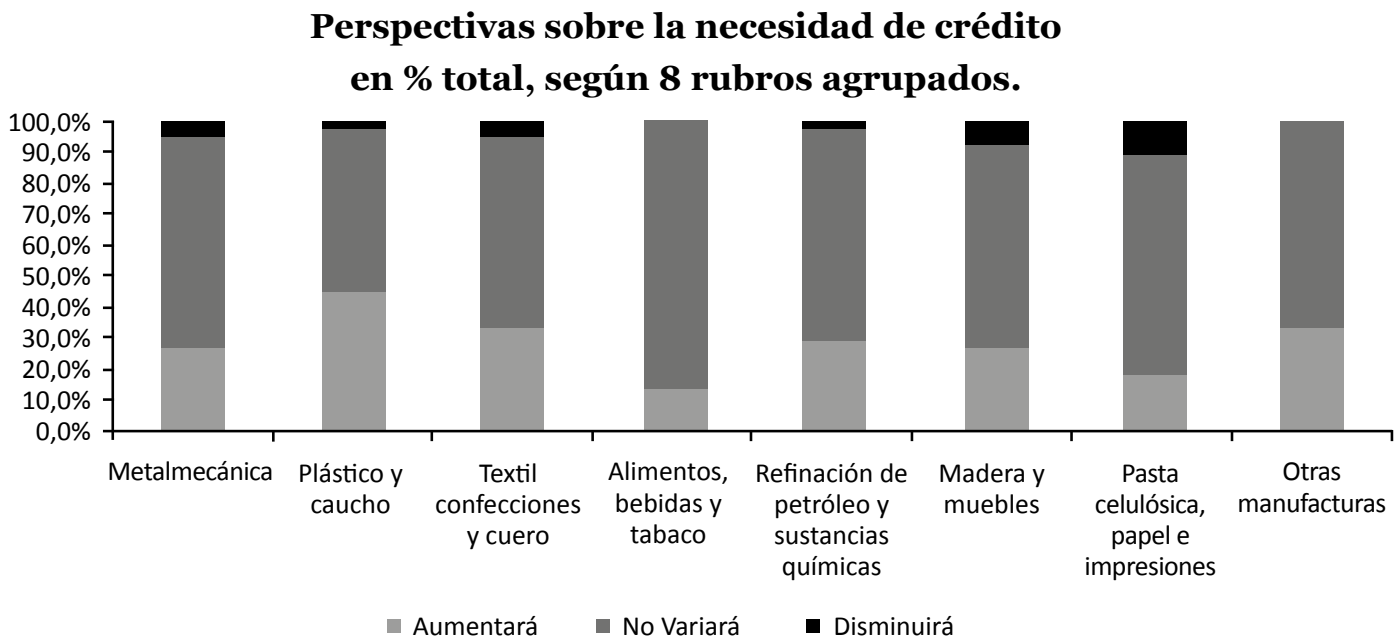

Fuente: Relevamiento Industrias del Partido de Gral. San Martín (Diciembre 2013).

A nivel nacional, el 49,5\% de las firmas no esperaba cambios significativos a esa fecha en sus necesidades crediticias para el primer trimestre de 2014.

\section{PERSONAL OCUPADO}

En cuanto al personal ocupado, el $84 \%$ de las empresas locales afirma que no variará su personal ocupado.

A nivel nacional, el 98,6\% de las empresas no esperaba cambios en la dotación de personal para el primer trimestre de 2014 y el 1,4\% preveía una suba. 
Gráfico 16. Perspectivas sobre el personal ocupado de las empresas del Partido de General San Martín.

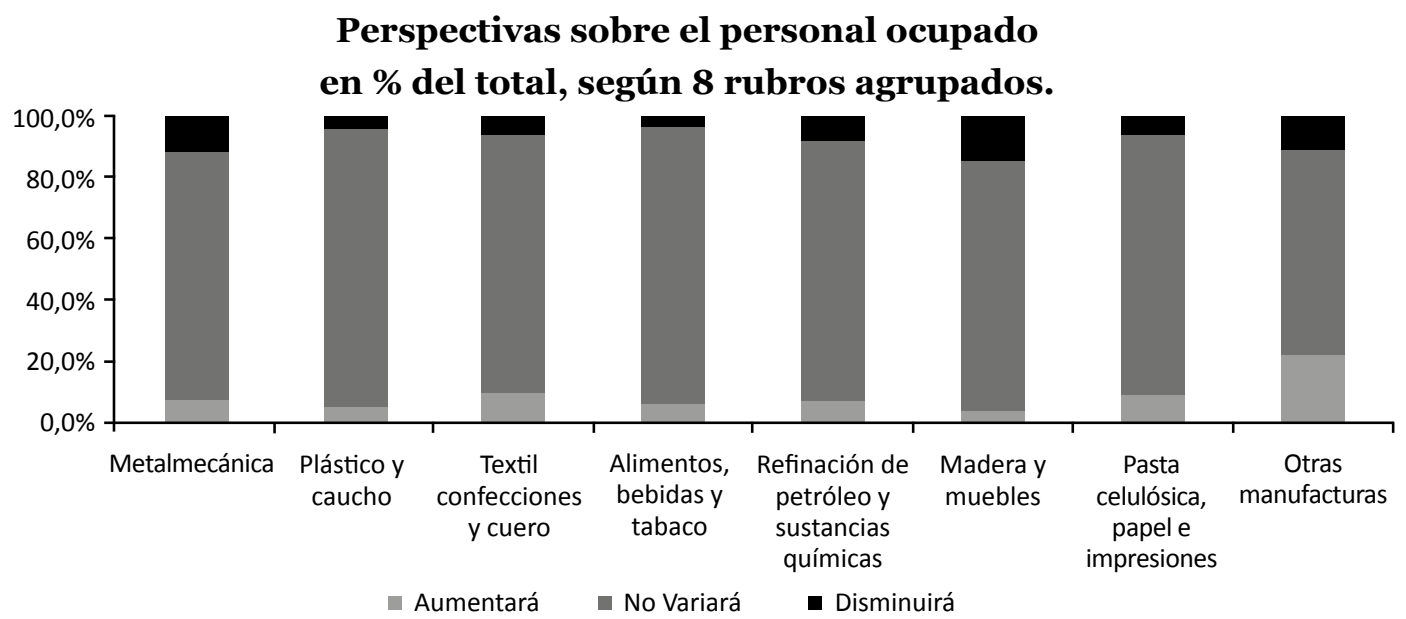

Fuente: Relevamiento Industrias del Partido de Gral. San Martín (Diciembre 2013).

\section{HORAS TRABAJADAS}

Respecto de las horas afectadas al personal ocupado, el 81\% de las empresas afirmó que las mismas no variarán. Coincide a nivel nacional, donde respecto de la cantidad de horas trabajadas del personal afectado al proceso productivo, el 80,9\% de las empresas no anticipaba cambios, el 11,3\% advertía una suba y el 7,8\% una disminución.

Gráfico 17. Perspectivas sobre las horas trabajadas del personal ocupado de las empresas del Partido de General San Martín.

\section{Perspectivas sobre las horas trabajadas} en \% del total, según 8 rubros agrupados.

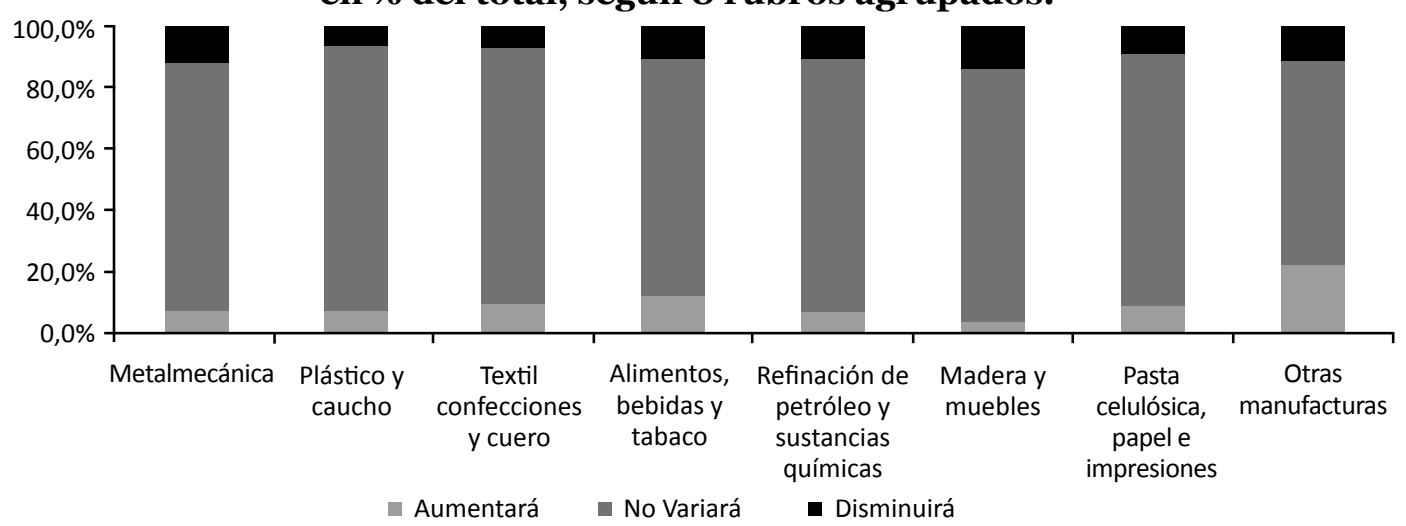

Fuente: Relevamiento Industrias del Partido de Gral. San Martín (Diciembre 2013). 


\section{ALGUNAS CONSIDERACIONES}

Se realizó una revisión del Censo Industrial San Martín 2005, a fin comparar la información presentada oportunamente sobre la composición de la estructura productiva, considerando que han pasado casi 10 años de la elaboración de dicho documento. En el mismo, se destacaban como principales industrias: la fabricación de productos de metal con un 22,3\%; la fabricación de productos textiles con un 11,6\% y la fabricación de productos de caucho y plástico con un $11,3 \%$. La diferencia con el relevamiento actual se presenta en el orden de importancia, entre estos dos últimos rubros.

Asimismo, en el censo se informaba que 8 sectores representaban el 76,7\% de los locales industriales del municipio. El 17,5\% de las empresas del partido eran exportadoras.

Respecto del personal ocupado, se estimaba un total de 38.200 personas, con un promedio de 19 personas ocupadas por empresa.

\section{ÁREAS DE INTERVENCIÓN:}

Teniendo en cuenta los principales rubros detectados en cuanto al peso en la composición de la estructura productiva (metalmecánica, caucho y plástico y textil) del Partido de General San Martín, es válido plantearse una serie de áreas de intervención para el fomento de la industria en el partido, muchas de las cuales corresponderían a la órbita nacional, pero otras podrían ser aplicables a nivel local.

\section{COMERCIO EXTERIOR}

Adquisiciones externas y sustitución de importaciones.

* Fomento para una estrategia sustitutiva que no sólo viabilice el ahorro de divisas, sino también un incremento de las escalas de producción de las pymes, una mayor integración de los ciclos productivos, ciertos senderos de aprendizaje y maduración tecnoproductiva, etc.

Exportaciones.

* Implementación de un programa de reducción de los derechos de exportación y/o de aumento de los reintegros a las exportaciones incrementales de maquinarias y equipamientos para la producción.

* Asistencia financiera como mecanismo de aliento a las ventas externas de bienes de capital fabricados en el país, incluyendo la prefinanciación, la financiación y la posfinanciación de exportaciones. Ello debe incluir una modificación en las condiciones de acceso al financiamiento, en los plazos del mismo y las tasas correspondientes.

Asistencia financiera.

* Líneas de crédito preferenciales y de largo plazo (con tasas subsidiadas) para orientar la inversión hacia bienes de capital de origen nacional.

Investigación, desarrollo e innovación. 
* Generación de instancias para facilitar el dictado de normas técnicas y verificar su cumplimiento.

* Instrumentación de políticas de promoción de certificaciones en el sector (o mejorar las existentes), de acuerdo con criterios locales de acreditación, pero que sean reconocidos en el nivel internacional.

Institucional.

*Fortalecimiento y mayor coordinación en el apoyo técnico y económico hacia el sector por parte de diversos organismos competentes, ya sean locales y/ o nacionales Deberían integrarse también las instituciones vinculadas con la problemática tecnológica y el desarrollo de actividades de investigación, desarrollo e innovación (Universidades, CONICET, INTA, INTI, IRAM, INET, etc).

Laboral.

* Implementación de programas con las instituciones vinculadas a la educación técnica como mecanismo para la masificación de la calificación de los trabajadores en saberes específicos y oficios.

* Otorgamiento de beneficios impositivos en cuanto a la incorporación o existencia de determinado porcentaje de mano de obra local en la nómina actual de la empresa.

* Desarrollo planes de becas en áreas definidas con compromisos de trabajo en firme durante un determinado período de tiempo.

\section{REFERENCIAS BIBLIOGRÁFICAS}

INDEC - Instituto Nacional de Estadísticas y Censo www.indec.gov.ar/

CLANAE - Clasificador Nacional de Actividades Económicas www.indec.mecon.ar/ micro_sitios/clanae/documentos\%5CNOTAS_METODOLOGICAS_CLANAE-2010.pdf

EMAE - Estimador Mensual de la Actividad Económica www.indec.gov.ar/nivel4_default.asp?id_tema_1=3\&id_tema_2=98id_tema_3=48

EMI - Estimador Mensual Industrial www.indec.gov.ar/nivel4_default.asp?id_ tema_1=3\&id_tema_2=68id_tema_3=14

Observatorio de Empleo y Dinámica Empresarial del Ministerio de Trabajo, Empleo y Seguridad Social de la Nación www.trabajo.gov.ar/left/estadisticas/oede/ 
Ministerio de Economía y Finanzas Públicas www.mecon.gov.ar/

Municipalidad de General San Martín: Sitio web oficial www.sanmartin.gov.ar

Gobierno de la Provincia de Buenos Aires. www.gba.gov.ar

Relevamiento Industrias del Partido de Gral. San Martín.

Parra Rueda, Susan, Diagnóstico del Sector Productivo del Partido de General San Martín, Provincia de Buenos Aires. "Insumos para la Agencia de Desarrollo Local. CISP ONG - en el marco del Proyecto PROMOVER. Abril 2010.

CIME - EEyN. Centro de Investigación y Medición Económica de la Escuela de Economía y Negocios-UNSAM. Relevamiento y análisis de la información en las áreas fiscal, monetaria, financiera, económica y social, correspondiente al partido de General San Martín. Buenos Aires, Argentina, Marzo 2006.

\section{CURRICULUM VITAE}

\section{Enrique Déntice}

Maestrando en Desarrollo Económico Local, UNSAM-UAM (Universidad Autónoma de Madrid). Coordinador CIME. Asesor externo Banco Mundial y Banco Interamericano de Desarrollo. Profesor concursado de Análisis Económico Aplicado, EEyN-UNSAM.

enrique.dentice@unsam.edu.ar

\section{Clara López}

Lic. en Administración y Gestión Empresarial, EEyN-UNSAM. Investigadora CIME-EEyNUNSAM. Coordinadora Panorama Económico y Financiero, CIME-EEyN. Docente concursada Economía, EEyN-UNSAM.

clara.lopez@unsam.edu.ar

\section{Leticia Busellini}

Maestrando en Desarrollo Local, UBA. Magister en Desarrollo Económico Local, UNSAMUAM. Asesora de la Secretaría de Industria de la Nación.

leticiabusellini@gmail.com 
ENRIQUE DÉNTICE - CLARA LÓPEZ - LETICIA BUSELLINI

$122<$ ENTRAMADO PRODUCTIVO DEL PARTIDO DE GENERAL SAN MARTÍN ANÁLISIS DE CASO

Pags. $96-127$

\begin{tabular}{|c|c|c|c|c|c|c|c|c|}
\hline \multirow{2}{*}{ Rubro } & \multicolumn{4}{|c|}{$\begin{array}{l}\text { Tamaño de industria en } \\
\text { San Martín } 2013 \text { - \% }\end{array}$} & \multicolumn{4}{|c|}{$\begin{array}{l}\text { Tamaño de industria a } \\
\text { nivel nacional } 2012 \text { - \% }\end{array}$} \\
\hline & Pequeña & Mediana & Grande & Total & Pequeña & Mediana & Grande & Total \\
\hline Alimentos & $92,90 \%$ & $5,70 \%$ & $1,40 \%$ & $100,00 \%$ & $93,10 \%$ & $5,20 \%$ & $1,70 \%$ & $100,00 \%$ \\
\hline Bebidas & $75,00 \%$ & $0,00 \%$ & $25,00 \%$ & $100,00 \%$ & & & & $100,00 \%$ \\
\hline Textil & $91,30 \%$ & $6,50 \%$ & $2,20 \%$ & $100,00 \%$ & $91,40 \%$ & $7,00 \%$ & $1,60 \%$ & $100,00 \%$ \\
\hline Prendas de vestir & $100,00 \%$ & $0,00 \%$ & $0,00 \%$ & $100,00 \%$ & $96,00 \%$ & $3,30 \%$ & $0,70 \%$ & $100,00 \%$ \\
\hline Cuero & $89,70 \%$ & $6,90 \%$ & $3,40 \%$ & $100,00 \%$ & $93,80 \%$ & $4,80 \%$ & $1,40 \%$ & $100,00 \%$ \\
\hline $\begin{array}{c}\text { Producción de madera y } \\
\text { fabricación de productos de } \\
\text { madera y corcho, excepto muebles }\end{array}$ & $91,70 \%$ & $4,20 \%$ & $4,20 \%$ & $100,00 \%$ & $97,20 \%$ & $2,50 \%$ & $0,30 \%$ & $100,00 \%$ \\
\hline $\begin{array}{l}\text { Fabricación de papel y } \\
\text { productos de papel }\end{array}$ & $87,50 \%$ & $12,50 \%$ & $0,00 \%$ & $100,00 \%$ & $86,20 \%$ & 10,70 & $3,10 \%$ & $100,00 \%$ \\
\hline $\begin{array}{l}\text { Edición e impresión; } \\
\text { reproducción de grabaciones }\end{array}$ & $96,70 \%$ & $0,00 \%$ & $3,30 \%$ & $100,00 \%$ & $95,60 \%$ & $3,60 \%$ & $0,90 \%$ & $100,00 \%$ \\
\hline Sustancias y productos químicos & $87,50 \%$ & $4,70 \%$ & $7,80 \%$ & $100,00 \%$ & $85,40 \%$ & $10,00 \%$ & $4,60 \%$ & $100,00 \%$ \\
\hline $\begin{array}{l}\text { Fabricación de productos } \\
\text { de caucho y plástico }\end{array}$ & $87,40 \%$ & $9,00 \%$ & $3,60 \%$ & $100,00 \%$ & $90,70 \%$ & $8,20 \%$ & $1,10 \%$ & $100,00 \%$ \\
\hline $\begin{array}{l}\text { Fabricación de productos } \\
\text { minerales no metálicos }\end{array}$ & $88,90 \%$ & $11,10 \%$ & $0,00 \%$ & $100,00 \%$ & $92,50 \%$ & $5,70 \%$ & $1,80 \%$ & $100,00 \%$ \\
\hline Fabricación de metales comunes & $100,00 \%$ & $0,00 \%$ & $0,00 \%$ & $100,00 \%$ & $91,20 \%$ & $7,30 \%$ & $1,60 \%$ & $100,00 \%$ \\
\hline $\begin{array}{c}\text { Fabricación de productos } \\
\text { elaborados de metal, excepto } \\
\text { maquinaria y equipo }\end{array}$ & $97,30 \%$ & $2,70 \%$ & $0,00 \%$ & $100,00 \%$ & $96,50 \%$ & $3,10 \%$ & $0,40 \%$ & $100,00 \%$ \\
\hline $\begin{array}{c}\text { Fabricación de equipos y } \\
\text { aparatos de radio, televisión } \\
\text { y comunicaciones }\end{array}$ & $92,10 \%$ & 6,30 & $1,60 \%$ & $100,00 \%$ & $84,40 \%$ & $7,10 \%$ & $8,40 \%$ & $100,00 \%$ \\
\hline $\begin{array}{l}\text { Fabricación de maquinaria y } \\
\text { aparatos eléctricos }\end{array}$ & $72,00 \%$ & 28,00 & $0,00 \%$ & $100,00 \%$ & $92,50 \%$ & $6,40 \%$ & $1,10 \%$ & $100,00 \%$ \\
\hline Fabricación de maquinaria y equipo & $66,70 \%$ & 0,00 & $33,30 \%$ & $100,00 \%$ & $92,40 \%$ & $6,20 \%$ & $1,40 \%$ & $100,00 \%$ \\
\hline $\begin{array}{l}\text { Fabricación de vehículos } \\
\text { automotores, remolques y } \\
\text { semirremolques }\end{array}$ & $74,20 \%$ & 16,10 & $9,70 \%$ & $100,00 \%$ & $84,60 \%$ & $10,90 \%$ & $4,50 \%$ & $100,00 \%$ \\
\hline $\begin{array}{l}\text { Fabricación de equipo de } \\
\text { transporte }\end{array}$ & $80,00 \%$ & 0,00 & $20,00 \%$ & $100,00 \%$ & $91,50 \%$ & $6,60 \%$ & $1,90 \%$ & $100,00 \%$ \\
\hline $\begin{array}{l}\text { Fabricación de muebles y } \\
\text { colchones }\end{array}$ & $94,50 \%$ & 5,50 & $0,00 \%$ & $100,00 \%$ & $96,10 \%$ & $3,30 \%$ & $0,60 \%$ & $100,00 \%$ \\
\hline Total & $91,20 \%$ & 6,30 & $2,50 \%$ & $100,00 \%$ & $93,30 \%$ & $5,20 \%$ & $1,40 \%$ & $100,00 \%$ \\
\hline
\end{tabular}




\begin{tabular}{|c|c|c|c|c|}
\hline Rubro & $\begin{array}{c}\text { Total de } \\
\text { personal ocupado - } \\
\text { San Martín } \\
\text { Diciembre } 2013 \\
\end{array}$ & $\begin{array}{l}\text { \% San Martín } \\
\text { Diciembre } 2013\end{array}$ & $\begin{array}{l}\text { Personal ocupado } \\
\text { en la Industria a } \\
\text { nivel Nacional - } \\
\text { 30 trimestre } 2013\end{array}$ & $\begin{array}{l}\text { \% a nivel Nacional - } \\
\text { 3o trimestre } 2013\end{array}$ \\
\hline Alimentos & 1.177 & $5,70 \%$ & 365.354 & $28,30 \%$ \\
\hline Bebidas & 241 & $1,20 \%$ & & $0,00 \%$ \\
\hline Textil & 2.644 & $12,70 \%$ & 69.058 & $5,40 \%$ \\
\hline Prendas de vestir & 76 & $0,40 \%$ & 49.135 & $3,80 \%$ \\
\hline Cuero & 891 & $4,30 \%$ & 43.314 & $3,40 \%$ \\
\hline \begin{tabular}{|c|} 
Producción de madera y \\
fabricación de productos de \\
madera y corcho, excepto muebles
\end{tabular} & 610 & $2,90 \%$ & 30.218 & $2,30 \%$ \\
\hline $\begin{array}{l}\text { Fabricación de papel y } \\
\text { productos de papel }\end{array}$ & 395 & $1,90 \%$ & 34.825 & $2,70 \%$ \\
\hline $\begin{array}{l}\text { Edición e impresión; } \\
\text { reproducción de grabaciones }\end{array}$ & 428 & $2,10 \%$ & 46.864 & $3,60 \%$ \\
\hline Sustancias y productos químicos & 2.099 & $10,10 \%$ & 116.213 & $9,00 \%$ \\
\hline $\begin{array}{l}\text { Fabricación de productos } \\
\text { de caucho y plástico }\end{array}$ & 3.638 & $17,50 \%$ & 67.317 & $5,20 \%$ \\
\hline $\begin{array}{l}\text { Fabricación de productos } \\
\text { minerales no metálicos }\end{array}$ & 197 & $0,90 \%$ & 46.072 & $3,60 \%$ \\
\hline Fabricación de metales comunes & 162 & $0,80 \%$ & 38.335 & $3,00 \%$ \\
\hline $\begin{array}{c}\text { Fabricación de productos } \\
\text { elaborados de metal, excepto } \\
\text { maquinaria y equipo }\end{array}$ & 2962 & $14,20 \%$ & 98.431 & $7,60 \%$ \\
\hline $\begin{array}{c}\text { Fabricación de equipos y } \\
\text { aparatos de radio, televisión } \\
\text { y comunicaciones }\end{array}$ & 239 & $1,10 \%$ & 4.529 & $0,40 \%$ \\
\hline $\begin{array}{c}\text { Fabricación de maquinaria y } \\
\text { aparatos eléctricos }\end{array}$ & 773 & $3,70 \%$ & 22.291 & $1,70 \%$ \\
\hline Fabricación de maquinaria y equipo & 1.317 & $6,30 \%$ & 72.993 & $5,70 \%$ \\
\hline $\begin{array}{l}\text { Fabricación de vehículos } \\
\text { automotores, remolques y } \\
\text { semirremolques }\end{array}$ & 1.596 & $7,70 \%$ & 89.909 & $7,00 \%$ \\
\hline $\begin{array}{l}\text { Fabricación de equipo de } \\
\text { transporte }\end{array}$ & 651 & $3,10 \%$ & 11.978 & $0,90 \%$ \\
\hline $\begin{array}{c}\text { Fabricación de muebles y } \\
\text { colchones }\end{array}$ & 690 & $3,30 \%$ & 38.117 & $3,00 \%$ \\
\hline Subtotal & 2.0786 & & 1.244 .953 & $96,60 \%$ \\
\hline Resto & & & 44.332 & $3,40 \%$ \\
\hline Total & 2.0786 & $100,00 \%$ & 1.289 .285 & $100,00 \%$ \\
\hline
\end{tabular}




\begin{tabular}{|c|c|c|c|c|}
\hline Rubro & $\begin{array}{c}\text { Empresas } \\
\text { relevadas }\end{array}$ & Exportan & No aplican & Porcentaje \\
\hline Fabricación de maquinaria y equipo & 45 & 23 & 22 & $51 \%$ \\
\hline Fabricación de vehículos automotores, remolques y semirremolques & 23 & 11 & 12 & $48 \%$ \\
\hline Fabricación de maquinaria y aparatos eléctricos & 16 & 5 & 11 & $31 \%$ \\
\hline Fabricación de papel y productos de papel & 19 & 5 & 14 & $26 \%$ \\
\hline Sustancias y productos químicos & 47 & 12 & 35 & $26 \%$ \\
\hline Fabricación de equipos y aparatos de radio, televisión y comunicaciones & 4 & 1 & 3 & $25 \%$ \\
\hline Fabricación de productos de caucho y plástico & 90 & 20 & 70 & $22 \%$ \\
\hline Fabricación de metales comunes & 11 & 2 & 9 & $18 \%$ \\
\hline Cuero & 25 & 4 & 21 & $16 \%$ \\
\hline Fabricación de productos elaborados de metal, & 183 & 29 & 154 & $16 \%$ \\
\hline excepto maquinaria y equipo & 70 & 10 & 60 & $14 \%$ \\
\hline Textil & 42 & 6 & 36 & $14 \%$ \\
\hline Fabricación de muebles y colchones & 8 & 1 & 7 & $13 \%$ \\
\hline Prendas de vestir & 9 & 1 & 8 & $11 \%$ \\
\hline Fabricación de productos minerales no metálicos & 19 & 2 & 17 & $11 \%$ \\
\hline Producción de madera y fabricación de productos & 25 & 2 & 23 & $8 \%$ \\
\hline de madera y corcho, excepto muebles & 49 & 1 & 48 & $2 \%$ \\
\hline Edición e impresión; reproducción de grabaciones & 4 & 0 & 4 & $0 \%$ \\
\hline Alimentos & $\mathbf{6 9 2}$ & $\mathbf{1 3 5}$ & $\mathbf{5 5 7}$ & $\mathbf{2 0 \%}$ \\
\hline Bebidas & & 3 & $0 \%$ \\
\hline Fabricación de equipo de transporte & & & 7 \\
\hline
\end{tabular}

\begin{tabular}{|c|c|c|c|c|}
\hline Rubro & $\begin{array}{l}\text { Empresas } \\
\text { relevadas }\end{array}$ & Importan & No aplican & Porcentaje \\
\hline Fabricación de equipos y aparatos de radio, televisión y comunicaciones & 4 & 3 & 1 & $75 \%$ \\
\hline Fabricación de equipo de transporte & 3 & 2 & 1 & $67 \%$ \\
\hline Fabricación de maquinaria y equipo & 45 & 27 & 18 & $60 \%$ \\
\hline Sustancias y productos químicos & 47 & 28 & 19 & $60 \%$ \\
\hline Fabricación de vehículos automotores, remolques y semirremolques & 23 & 13 & 10 & $57 \%$ \\
\hline Fabricación de maquinaria y aparatos eléctricos & 16 & 7 & 9 & $44 \%$ \\
\hline Fabricación de papel y productos de papel & 19 & 8 & 11 & $42 \%$ \\
\hline Fabricación de productos de caucho y plástico & 89 & 36 & 53 & $40 \%$ \\
\hline Fabricación de productos minerales no metálicos & 9 & 3 & 6 & $33 \%$ \\
\hline $\begin{array}{l}\text { Producción de madera y fabricación de productos } \\
\text { de madera y corcho, excepto muebles }\end{array}$ & 19 & 6 & 13 & $32 \%$ \\
\hline Textil & 70 & 22 & 48 & $31 \%$ \\
\hline Fabricación de productos elaborados de metal, excepto maquinaria y equipo & 183 & 50 & 133 & $27 \%$ \\
\hline Fabricación de metales comunes & 11 & 3 & 8 & $27 \%$ \\
\hline Prendas de vestir & 8 & 2 & 6 & $25 \%$ \\
\hline Cuero & 25 & 6 & 19 & $24 \%$ \\
\hline Edición e impresión; reproducción de grabaciones & 25 & 6 & 18 & $24 \%$ \\
\hline Fabricación de muebles y colchones & 42 & 7 & 36 & $17 \%$ \\
\hline Alimentos & 49 & 5 & 44 & $10 \%$ \\
\hline Bebidas & 4 & 0 & 4 & $0 \%$ \\
\hline Total & 691 & 234 & 457 & $34 \%$ \\
\hline
\end{tabular}




\begin{tabular}{|c|c|c|c|}
\hline \multirow[b]{2}{*}{ Rubro } & \multicolumn{2}{|c|}{$\begin{array}{c}\text { Utilizaron el } 100 \% \\
\text { de sus Instalaciones? }\end{array}$} & \multirow[b]{2}{*}{$\begin{array}{l}\text { Empresas } \\
\text { relevadas }\end{array}$} \\
\hline & Si & No & \\
\hline Alimentos & $43 \%$ & $57 \%$ & $100 \%$ \\
\hline Bebidas & $75 \%$ & $25 \%$ & $100 \%$ \\
\hline Fabricación de productos textiles & $38 \%$ & $62 \%$ & $100 \%$ \\
\hline Prendas de vestir & $44 \%$ & $56 \%$ & $100 \%$ \\
\hline Cuero & $36 \%$ & $64 \%$ & $100 \%$ \\
\hline Producción de madera y fabricación de productos de madera y corcho, excepto muebles & $32 \%$ & $68 \%$ & $100 \%$ \\
\hline Fabricación de papel y productos de papel & $47 \%$ & $53 \%$ & $100 \%$ \\
\hline Edición e impresión; reproducción de grabaciones & $29 \%$ & $71 \%$ & $100 \%$ \\
\hline Sustancias y productos químicos & $36 \%$ & $64 \%$ & $100 \%$ \\
\hline Fabricación de productos de caucho y plástico & $36 \%$ & $64 \%$ & $100 \%$ \\
\hline Fabricación de productos minerales no metálicos & $56 \%$ & $44 \%$ & $100 \%$ \\
\hline Fabricación de metales comunes & $25 \%$ & $75 \%$ & $100 \%$ \\
\hline Fabricación de productos elaborados de metal, excepto maquinaria y equipo & $28 \%$ & $72 \%$ & $100 \%$ \\
\hline Fabricación de equipos y aparatos de radio, televisión y comunicaciones & $39 \%$ & $61 \%$ & $100 \%$ \\
\hline Fabricación de maquinaria y aparatos eléctricos & $31 \%$ & $69 \%$ & $100 \%$ \\
\hline Fabricación de maquinaria y equipo & $25 \%$ & $75 \%$ & $100 \%$ \\
\hline Fabricación de vehículos automotores, remolques y semirremolques & $22 \%$ & $78 \%$ & $100 \%$ \\
\hline Fabricación de equipo de transporte & $33 \%$ & $67 \%$ & $100 \%$ \\
\hline Fabricación de muebles y colchones & $24 \%$ & $76 \%$ & $100 \%$ \\
\hline Total & $34 \%$ & $66 \%$ & $100 \%$ \\
\hline
\end{tabular}

\begin{tabular}{|c|c|c|c|c|}
\hline Rubro & Aumentó & No Varió & Disminuyó & Total \\
\hline Alimentos & $12 \%$ & $29 \%$ & $59 \%$ & $100 \%$ \\
\hline Bebidas & $25 \%$ & $25 \%$ & $50 \%$ & $100 \%$ \\
\hline Textil & $26 \%$ & $33 \%$ & $41 \%$ & $100 \%$ \\
\hline Prendas de vestir & $38 \%$ & $38 \%$ & $25 \%$ & $100 \%$ \\
\hline Cuero & $20 \%$ & $44 \%$ & $36 \%$ & $100 \%$ \\
\hline $\begin{array}{l}\text { Producción de madera y fabricación de productos de madera y corcho, } \\
\text { excepto muebles }\end{array}$ & $11 \%$ & $32 \%$ & $58 \%$ & $100 \%$ \\
\hline Fabricación de papel y productos de papel & $11 \%$ & $63 \%$ & $26 \%$ & $100 \%$ \\
\hline Edición e impresión; reproducción de grabaciones & $24 \%$ & $28 \%$ & $48 \%$ & $100 \%$ \\
\hline Sustancias y productos químicos & $15 \%$ & $34 \%$ & $51 \%$ & $100 \%$ \\
\hline Fabricación de productos de caucho y plástico & $37 \%$ & $31 \%$ & $32 \%$ & $100 \%$ \\
\hline Fabricación de productos minerales no metálicos & $44 \%$ & $33 \%$ & $22 \%$ & $100 \%$ \\
\hline Fabricación de metales comunes & $27 \%$ & $45 \%$ & $27 \%$ & $100 \%$ \\
\hline Fabricación de productos elaborados de metal, excepto maquinaria y equipo & $19 \%$ & $27 \%$ & $54 \%$ & $100 \%$ \\
\hline Fabricación de equipos y aparatos de radio, televisión y comunicaciones & $25 \%$ & $25 \%$ & $50 \%$ & $100 \%$ \\
\hline Fabricación de maquinaria y aparatos eléctricos & $31 \%$ & $25 \%$ & $44 \%$ & $100 \%$ \\
\hline Fabricación de maquinaria y equipo & $16 \%$ & $33 \%$ & $51 \%$ & $100 \%$ \\
\hline Fabricación de vehículos automotores, remolques y semirremolques & $30 \%$ & $17 \%$ & $52 \%$ & $100 \%$ \\
\hline Fabricación de equipo de transporte & $33 \%$ & $33 \%$ & $33 \%$ & $100 \%$ \\
\hline Fabricación de muebles y colchones & $10 \%$ & $24 \%$ & $67 \%$ & $100 \%$ \\
\hline Total & $22 \%$ & $31 \%$ & $47 \%$ & $100 \%$ \\
\hline
\end{tabular}




\begin{tabular}{|c|c|c|c|c|}
\hline \multicolumn{5}{|c|}{ Expectativas de tratamiento del stock de productos terminados } \\
\hline Rubro & Aumentó & No Varió & Disminuyó & Total \\
\hline Alimentos & $8 \%$ & $58 \%$ & $33 \%$ & $100 \%$ \\
\hline Bebidas & $0 \%$ & $50 \%$ & $50 \%$ & $100 \%$ \\
\hline Textil & $26 \%$ & $47 \%$ & $26 \%$ & $100 \%$ \\
\hline Prendas de vestir & $0 \%$ & $50 \%$ & $50 \%$ & $100 \%$ \\
\hline Cuero & $13 \%$ & $38 \%$ & $50 \%$ & $100 \%$ \\
\hline $\begin{array}{l}\text { Producción de madera y fabricación de productos de madera y corcho, } \\
\text { excepto muebles }\end{array}$ & $13 \%$ & $25 \%$ & $63 \%$ & $100 \%$ \\
\hline Fabricación de papel y productos de papel & $11 \%$ & $56 \%$ & $33 \%$ & $100 \%$ \\
\hline Edición e impresión; reproducción de grabaciones & $33 \%$ & $67 \%$ & $0 \%$ & $100 \%$ \\
\hline Sustancias y productos químicos & $21 \%$ & $52 \%$ & $28 \%$ & $100 \%$ \\
\hline Fabricación de productos de caucho y plástico & $22 \%$ & $57 \%$ & $20 \%$ & $100 \%$ \\
\hline Fabricación de productos minerales no metálicos & $29 \%$ & $43 \%$ & $29 \%$ & $100 \%$ \\
\hline Fabricación de metales comunes & $0 \%$ & $100 \%$ & $0 \%$ & $100 \%$ \\
\hline Fabricación de productos elaborados de metal, excepto maquinaria y equipo & $17 \%$ & $47 \%$ & $36 \%$ & $100 \%$ \\
\hline Fabricación de equipos y aparatos de radio, televisión y comunicaciones & $0 \%$ & $100 \%$ & $0 \%$ & $100 \%$ \\
\hline Fabricación de maquinaria y aparatos eléctricos & $8 \%$ & $58 \%$ & $33 \%$ & $100 \%$ \\
\hline Fabricación de maquinaria y equipo & $5 \%$ & $36 \%$ & $59 \%$ & $100 \%$ \\
\hline Fabricación de vehículos automotores, remolques y semirremolques & $15 \%$ & $54 \%$ & $31 \%$ & $100 \%$ \\
\hline Fabricación de equipo de transporte & $0 \%$ & $100 \%$ & $0 \%$ & $100 \%$ \\
\hline Fabricación de muebles y colchones & $21 \%$ & $14 \%$ & $64 \%$ & $100 \%$ \\
\hline Total & $18 \%$ & $49 \%$ & $34 \%$ & $100 \%$ \\
\hline
\end{tabular}

\begin{tabular}{|c|c|c|c|c|}
\hline \multicolumn{1}{|c|}{ Rubro } & \multicolumn{3}{|c|}{ Perspectivas sobre la necesidad de crédito } \\
\hline Alimentos & Aumentó & No Varió & Disminuyó & Total \\
\hline Bebidas & $10 \%$ & $90 \%$ & $0 \%$ & $100 \%$ \\
\hline Textil & $50 \%$ & $50 \%$ & $0 \%$ & $100 \%$ \\
\hline Prendas de vestir & $40 \%$ & $54 \%$ & $6 \%$ & $100 \%$ \\
\hline Cuero & $0 \%$ & $100 \%$ & $0 \%$ & $100 \%$ \\
\hline excepto muebles & $24 \%$ & $72 \%$ & $4 \%$ & $100 \%$ \\
\hline Producción de madera y fabricacín de productos de madera y corcho, & $32 \%$ & $53 \%$ & $16 \%$ & $100 \%$ \\
\hline Fabricación de papel y productos de papel & $26 \%$ & $58 \%$ & $16 \%$ & $100 \%$ \\
\hline Sustancias y productos químicos & $12 \%$ & $80 \%$ & $8 \%$ & $100 \%$ \\
\hline Fabrimpresión; reproducción de grabaciones & $30 \%$ & $68 \%$ & $2 \%$ & $100 \%$ \\
\hline Fabricación de metales comunes & $44 \%$ & $53 \%$ & $2 \%$ & $100 \%$ \\
\hline Fabricación de productos elaborados de metal, excepto maquinaria y equipo & $27 \%$ & $68 \%$ & $5 \%$ & $100 \%$ \\
\hline Fabricación de equipos y aparatos de radio, televisión y comunicaciones & $75 \%$ & $25 \%$ & $0 \%$ & $100 \%$ \\
\hline Fabricación de maquinaria y aparatos eléctricos & $38 \%$ & $56 \%$ & $6 \%$ & $100 \%$ \\
\hline Fabricación de maquinaria y equipo & $27 \%$ & $67 \%$ & $7 \%$ & $100 \%$ \\
\hline Fabricación de equipo de transporte & $26 \%$ & $74 \%$ & $0 \%$ & $100 \%$ \\
\hline Fabricación de muebles y colchones & $33 \%$ & $67 \%$ & $0 \%$ & $100 \%$ \\
\hline Fabricación de vehículos & $24 \%$ & $71 \%$ & $5 \%$ & $100 \%$ \\
\hline & $\mathbf{2 9} \%$ & $\mathbf{6 7} \%$ & $\mathbf{5} \%$ & $\mathbf{1 0 0} \%$ \\
\hline
\end{tabular}




\begin{tabular}{|c|c|c|c|c|}
\hline \multirow[t]{2}{*}{ Rubro } & \multicolumn{4}{|c|}{ Perspectivas sobre personal ocupado } \\
\hline & Aumentó & No Varió & Disminuyó & Total \\
\hline Alimentos & $6 \%$ & $90 \%$ & $4 \%$ & $100 \%$ \\
\hline Bebidas & $0 \%$ & $100 \%$ & $0 \%$ & $100 \%$ \\
\hline Fabricación de productos textiles & $13 \%$ & $83 \%$ & $4 \%$ & $100 \%$ \\
\hline Prendas de vestir & $0 \%$ & $86 \%$ & $14 \%$ & $100 \%$ \\
\hline Cuero & $4 \%$ & $84 \%$ & $12 \%$ & $100 \%$ \\
\hline $\begin{array}{l}\text { Producción de madera y fabricación de productos de madera y corcho, } \\
\text { excepto muebles }\end{array}$ & $5 \%$ & $79 \%$ & $16 \%$ & $100 \%$ \\
\hline Fabricación de papel y productos de papel & $0 \%$ & $100 \%$ & $0 \%$ & $100 \%$ \\
\hline Edición e impresión; reproducción de grabaciones & $16 \%$ & $72 \%$ & $12 \%$ & $100 \%$ \\
\hline Sustancias y productos químicos & $6 \%$ & $85 \%$ & $9 \%$ & $100 \%$ \\
\hline Fabricación de productos de caucho y plástico & $6 \%$ & $90 \%$ & $4 \%$ & $100 \%$ \\
\hline Fabricación de productos minerales no metálicos & $22 \%$ & $67 \%$ & $11 \%$ & $100 \%$ \\
\hline Fabricación de metales comunes & $9 \%$ & $82 \%$ & $9 \%$ & $100 \%$ \\
\hline Fabricación de productos elaborados de metal, excepto maquinaria y equipo & $8 \%$ & $80 \%$ & $12 \%$ & $100 \%$ \\
\hline Fabricación de equipos y aparatos de radio, televisión y comunicaciones & $25 \%$ & $50 \%$ & $25 \%$ & $100 \%$ \\
\hline Fabricación de maquinaria y aparatos eléctricos & $0 \%$ & $88 \%$ & $13 \%$ & $100 \%$ \\
\hline Fabricación de maquinaria y equipo & $7 \%$ & $80 \%$ & $14 \%$ & $100 \%$ \\
\hline Fabricación de vehículos automotores, remolques y semirremolques & $4 \%$ & $87 \%$ & $9 \%$ & $100 \%$ \\
\hline Fabricación de equipo de transporte & $0 \%$ & $100 \%$ & $0 \%$ & $100 \%$ \\
\hline Fabricación de muebles y colchones & $2 \%$ & $83 \%$ & $14 \%$ & $100 \%$ \\
\hline Total & $7 \%$ & $84 \%$ & $9 \%$ & $100 \%$ \\
\hline
\end{tabular}

\begin{tabular}{|c|c|c|c|c|}
\hline \multirow[t]{2}{*}{ Rubro } & \multicolumn{4}{|c|}{ Perspectivas sobre horas trabajadas } \\
\hline & Aumentó & No Varió & Disminuyó & Total \\
\hline Alimentos & $10 \%$ & $78 \%$ & $12 \%$ & $100 \%$ \\
\hline Bebidas & $25 \%$ & $75 \%$ & $0 \%$ & $100 \%$ \\
\hline Fabricación de productos textiles & $13 \%$ & $81 \%$ & $6 \%$ & $100 \%$ \\
\hline Prendas de vestir & $0 \%$ & $88 \%$ & $13 \%$ & $100 \%$ \\
\hline Cuero & $4 \%$ & $84 \%$ & $12 \%$ & $100 \%$ \\
\hline $\begin{array}{l}\text { Producción de madera y fabricación de productos de madera y corcho, } \\
\text { excepto muebles }\end{array}$ & $11 \%$ & $79 \%$ & $11 \%$ & $100 \%$ \\
\hline Fabricación de papel y productos de papel & $0 \%$ & $95 \%$ & $5 \%$ & $100 \%$ \\
\hline Edición e impresión; reproducción de grabaciones & $16 \%$ & $72 \%$ & $12 \%$ & $100 \%$ \\
\hline Sustancias y productos químicos & $6 \%$ & $83 \%$ & $11 \%$ & $100 \%$ \\
\hline Fabricación de productos de caucho y plástico & $7 \%$ & $87 \%$ & $7 \%$ & $100 \%$ \\
\hline Fabricación de productos minerales no metálicos & $22 \%$ & $67 \%$ & $11 \%$ & $100 \%$ \\
\hline Fabricación de metales comunes & $0 \%$ & $91 \%$ & $9 \%$ & $100 \%$ \\
\hline Fabricación de productos elaborados de metal, excepto maquinaria y equipo & $9 \%$ & $78 \%$ & $13 \%$ & $100 \%$ \\
\hline Fabricación de equipos y aparatos de radio, televisión y comunicaciones & $25 \%$ & $50 \%$ & $25 \%$ & $100 \%$ \\
\hline Fabricación de maquinaria y aparatos eléctricos & $0 \%$ & $94 \%$ & $6 \%$ & $100 \%$ \\
\hline Fabricación de maquinaria y equipo & $7 \%$ & $75 \%$ & $18 \%$ & $100 \%$ \\
\hline Fabricación de vehículos automotores, remolques y semirremolques & $4 \%$ & $91 \%$ & $4 \%$ & $100 \%$ \\
\hline Fabricación de equipo de transporte & $0 \%$ & $100 \%$ & $0 \%$ & $100 \%$ \\
\hline Fabricación de muebles y colchones & $0 \%$ & $83 \%$ & $17 \%$ & $100 \%$ \\
\hline Total & $8 \%$ & $81 \%$ & $11 \%$ & $100 \%$ \\
\hline
\end{tabular}

